\title{
Digital Twin Driven Green Performance Evaluation Methodology of Intelligent Manufacturing: Hybrid Model Based on Fuzzy Rough-Sets AHP, Multistage Weight Synthesis, and PROMETHEE II
}

\author{
Lianhui Li $\mathbb{D}$, ${ }^{1,2,3}$ Chunlei Mao, ${ }^{4}$ Hongxia Sun, ${ }^{1}$ Yiping Yuan $\mathbb{D},{ }^{5}$ and Bingbing Lei $\mathbb{C}^{2,6}$ \\ ${ }^{1}$ College of Mechatronic Engineering, North Minzu University, Yinchuan 750021, China \\ ${ }^{2}$ Ningxia Key Laboratory of Intelligent Information and Big Data Processing, North Minzu University, Yinchuan 750021, China \\ ${ }^{3}$ Institute of Physical Internet, Jinan University, Zhuhai 519070, China \\ ${ }^{4}$ Nanjing Automation Institute of Water Conservancy and Hydrology, Nanjing 210012, China \\ ${ }^{5}$ School of Mechanical Engineering, Xinjiang University, Urumqi 830046, China \\ ${ }^{6}$ School of Computer Science and Engineering, North Minzu University, Yinchuan 750021, China \\ Correspondence should be addressed to Bingbing Lei; x_generation@126.com
}

Received 24 March 2020; Accepted 22 June 2020; Published 16 July 2020

Guest Editor: Baogui Xin

Copyright (c) 2020 Lianhui Li et al. This is an open access article distributed under the Creative Commons Attribution License, which permits unrestricted use, distribution, and reproduction in any medium, provided the original work is properly cited.

\begin{abstract}
The design, planning, and implementation of intelligent manufacturing are mainly carried out from the perspectives of meeting the needs of mass customization, improving manufacturing capacity, and innovating business pattern currently. Environmental and social factors should be systematically integrated into the life cycle of intelligent manufacturing. In view of this, a green performance evaluation methodology of intelligent manufacturing driven by digital twin is proposed in this paper. Digital twin framework, which constructs the bidirectional mapping and real-time data interaction between physical entity and digital model, provides the green performance evaluation with a total factor virtual image of the whole life cycle to meet the monitoring and simulation requirements of the evaluation information source and demand. Driven by the digital twin framework, a novel hybrid MCDM model based on fuzzy rough-sets AHP, multistage weight synthesis, and PROMETHEE II is proposed as the methodology for the green performance evaluation of intelligent manufacturing. The model is tested and validated on a study of the green performance evaluation of remote operation and maintenance service project evaluation for an air conditioning enterprise. Testing demonstrates that the proposed hybrid model driven by digital twin can enable a stable and reasonable evaluation result. A sensitivity analysis was carried out by means of 27 scenarios, the results of which showed a high degree of stability.
\end{abstract}

\section{Introduction}

The concept of intelligent manufacturing rose in the 1980s. Its emergence and development are closely related to the four industrial revolutions and the development of related technologies and industries. First of all, the first and second industrial revolutions brought manufacturing industry into the era of mechanization and electrification. With the invention and application of atomic energy and electronic computer technology, the third industrial revolution appeared. In the same period, terms representing new manufacturing paradigms such as flexible manufacturing cells (FMCs) [1], flexible manufacturing systems (FMSs) [2], computer integrated manufacturing (CIM) [3], and intelligent manufacturing system (IMS) [4] are emerging gradually. After more than 40 years of development and progress, intelligent manufacturing has gradually evolved from concept to industrialization and integrated into the emerging fourth industrial revolution.

At present, the design and implementation of intelligent manufacturing are mainly carried out from the perspectives of meeting the needs of mass customization, improving 
manufacturing capacity, and innovating business pattern. In some theoretical research and practice, green or even sustainability has also been brought into the intelligent manufacturing paradigm. But most of them focus on the optimization of energy consumption in the manufacturing process. For example, cloud platform is used for promoting resource sharing and improving application efficiency of manufacturing system [5]; combining big data technology in the product life cycle to achieve sustainable intelligent manufacturing is proposed [6]; big data method was used for energy efficiency optimization [7], anomaly detection [8], and energy consumption monitoring [9] in intelligent manufacturing process; and through the analysis of relevant literature, it can be seen that there is no clear definition of green intelligent manufacturing in the current academic circle, and few research studies systematically integrated environmental and social factors into the design, planning, and implementation of intelligent manufacturing $[10,11]$. On the one hand, the current research and practice pay more attention to the core business and competitive elements (for example, productivity improvement, personalized customization, and intelligent services). On the other hand, the improvement of the environment and social impact of intelligent manufacturing may conflict with the realization of other elements and even may bring a lot of investment costs. The research on the green of intelligent manufacturing is still in the exploratory stage.

At present, there are many researches on performance evaluation of intelligent manufacturing, focusing on the following aspects.

The first aspect is overall performance evaluation of intelligent manufacturing enterprises. Gong [12] introduced a three-tier index system to evaluate the performance of enterprise intelligent manufacturing by using the comprehensive scoring method of experts, which covers many aspects of enterprise performance, but does not involve environmental performance, and only uses an overall satisfaction degree for the evaluation of employees. Jia and Shi [13] use the DEA model of cross efficiency to measure the performance of some listed intelligent manufacturing enterprises, which can evaluate the overall economic performance of enterprises, but cannot pay attention to the details of intelligent manufacturing itself, and does not consider the environmental factors.

In the second aspect, enterprise's intelligent manufacturing capability is assessed. Yi et al. [14] established the evaluation model of enterprise intelligent manufacturing capability based on tensor analysis and measured the enterprise intelligent manufacturing capability from three dimensions of life cycle, system level, and intelligent function. Similarly, Ding et al. [15] put forward the intelligent manufacturing capability maturity model from three dimensions of manufacturing resources, manufacturing assurance, and intelligent promotion, which can support enterprises to describe their comprehensive level of intelligent manufacturing. Qu et al. [16] used Douglas production function and seemingly unrelated regression (SUA) analysis to evaluate the production capacity of intelligent manufacturing enterprises, so as to compare its advantages and disadvantages with traditional manufacturing capacity. Schumacher et al. [17] proposed an empirical model to evaluate the industry 4.0 maturity of discrete manufacturing enterprise, in which nine dimensions and sixty-two indicators were established for evaluation, including the items of the impact on employees and products.

The third aspect is environment and social impact assessment of intelligent manufacturing. There are few research studies on intelligent manufacturing environment and social impact assessment. The above two aspects or part of the performance assurance research of intelligent manufacturing involved environmental and social dimensions, but it was often described as a macromethod only including environmental or social factors as a macroindicator [18].

In addition, Mashhadi and Behdad [19] summarized the shortcomings of traditional life cycle assessment (LCA) in the assessment of the environment impact of intelligent manufacturing, combined with the characteristics of intelligent manufacturing, and put forward the assessment concept based on product characteristics data. It is mainly a scheme of data collection and real-time assessment by using the new generation of information technology, rather than studying specific assessment methods. Peruzzini et al. [20] used social life cycle assessment (SLCA) to evaluate the impact of the implementation of intelligent manufacturing on the society, but it only focuses on the general social impact, not the special impact of intelligent manufacturing on employees or users.

By creating the virtual model of physical entity in a digital way and simulating the behavior of physical entity by means of data, digital twin has the characteristics of realtime synchronization, faithful mapping and high fidelity through the means of virtual real interaction feedback, data fusion analysis, and decision iteration selection optimization [21]. Digital twin can promote the interaction and integration of physical world and information world and increase or expand new capabilities for physical entity [22]. In this study, digital twin mainly focuses on obtaining the virtual image of all factors in the whole life cycle of intelligent manufacturing project to meet the monitoring and simulation requirements of the evaluation information source and demand for the green evaluation of intelligent manufacturing. Based on digital twin technology [21, 22], the complete and dynamic mapping interaction between physical entity and digital model in green performance evaluation of intelligent manufacturing can be realized. And then, how to comprehensively master the multidimensional influencing factors and their coupling relationship for comparative analysis is the key problem in green performance evaluation of intelligent manufacturing.

Multicriteria decision-making (MCDM) [23, 24] by using the experience and wisdom of experts is a feasible method to comprehensively consider the multidimensional influencing factors and their coupling relationship that affect the green performance evaluation. In the existing similar evaluation problem and its solution, the value or importance of a factor is usually evaluated by one expert in numerical number form, which is unreasonable due to the preferences 
of individual expert and the fuzziness of expert judgment $[25,26]$. Additionally, the green performance evaluation of intelligent manufacturing includes multidimensional influencing factors with complex coupling relationship, and these factors and their relationship are dynamic evolution. Therefore, it is difficult for a single expert to achieve accurate judgment with the numerical number form as the judgment opinion, while integrating the fuzzy number form judgment of multiple experts is more reasonable. Trapezoid fuzzy number, which is a key definition in fuzzy theory, can reflect the internal uncertainty of expert's judgment $[27,28]$. To express the expert judgment value about the value or importance of the index, using trapezoid fuzzy number can better describe the uncertainty. The single weight method cannot fully reflect the weight information. The weights obtained by the multiple weight method should be synthesized.

To sum up, there is a lack of special, systematic, and objective research to evaluate the green performance of intelligent manufacturing. The existing studies prove the necessity of green performance evaluation of intelligent manufacturing and provide reference for the study of this paper. Additionally, digital twin can provide an overall information framework for this study. In view of this, this paper constructs an overall information framework driven by digital twin for the green performance of intelligent manufacturing. In this framework, the digital twin system is formed by mapping and interacting between intelligent manufacturing entity and intelligent manufacturing model. All activities in the life cycle of intelligent manufacturing entity interact with the model in real time, and both physical entity and digital model provide a source of digital twin data. With the full mastery of digital twin data by multiple experts, a novel hybrid MCDM model based on fuzzy rough-sets AHP, multistage weight synthesis, and PROMETHEE II (FRSA-MSWS-PII) is proposed as the methodology for the green performance evaluation of intelligent manufacturing.

The rest of this work is arranged as follows: overall framework driven by digital twin is stated in Section 2; Section 3 builds the novel hybrid MCDM model (FRSAMSWS-PII) for the green performance evaluation of intelligent manufacturing, which include three phases: multiexpert judgment integration based on fuzzy rough-sets AHP, multistage weight synthesis, and intelligent manufacturing project evaluation by PROMETHEE II; case study is given in Section 4 by an application of remote operation and maintenance service project evaluation for an air conditioning enterprise; Section 5 presents a discussion of the results and validation of the FRSA-MSWS-PII model; finally, Section 6 summarizes the conclusion.

\section{Overall Framework}

On the basis of digital twin technology [21, 22], the bidirectional mapping and real-time data interaction are constructed between physical entity and digital model. Therefore, the comprehensive data integration and fusion of physical entity and digital model can be realized and form the digital twin data that can support and drive the green performance evaluation methodology. In addition, the green performance evaluation methodology results in an optimal project alternative selection, which can interact with the physical entity and digital model and provide the physical entity and digital model with the support of decisionmaking. The overall framework built in this paper is driven by digital twin. As shown in Figure 1, it consists of three layers, which are the digital twin concept layer, information layer, and methodology layer.

The bidirectional mapping and real-time data interaction between physical entity and digital model are defined theoretically in the digital twin concept layer. In the design stage of intelligent manufacturing project, multiple project alternatives are produced in general. All of them meet the actual demands. After that, in the test running stage, the original intelligent manufacturing project will be adjusted and optimized iteratively. Finally, an optimal alternative is determined and put into formal running stage. Additionally, the data of formal running stage will also be fed back to assist in the selection optimization of design stage.

Intelligent manufacturing project entity really exists in the physical world, while intelligent manufacturing project model is a real and complete digital mirror image of intelligent manufacturing project entity. Intelligent manufacturing project model can integrate all influencing factors related to green performance evaluation of intelligent manufacturing project. At the same time, it is a dynamic model, which can describe the dynamic evolution of the whole life cycle including but not limited to the design, test running, and formal running stages.

\section{Hybrid MCDM Model (FRSA-MSWS-PII)}

3.1. Fundamental Concepts. The fundamental concepts in the proposed hybrid model mainly include two aspects: trapezoid fuzzy number (TFN) related to fuzzy mathematics, rough approximation set (RAS), and rough boundary interval (RBI) related to rough-sets theory $[27,28]$.

3.1.1. Trapezoid Fuzzy Number (TFN). A TFN is defined as follows:

$$
\tilde{a}=(\alpha, \chi, \delta, \beta) .
$$

Its membership function $f_{\widetilde{a}}(x): R \longrightarrow[0,1]$ is defined as follows:

$$
f_{\tilde{a}}(x)= \begin{cases}\frac{x-\alpha}{\chi-\alpha}, & \alpha \leq x \leq \chi, \\ 1, & \chi \leq x \leq \delta, \\ \frac{x-\beta}{\delta-\beta}, & \delta \leq x \leq \beta, \\ 0, & x<\alpha \text { or } x>\beta,\end{cases}
$$

where $x \in R, \alpha \leq \chi \leq \delta \leq \beta$, and $\alpha$ and $\beta$ are the lower bound and upper bound of $\widetilde{a}$, respectively. Especially, when $\chi=\delta, \widetilde{a}$ 


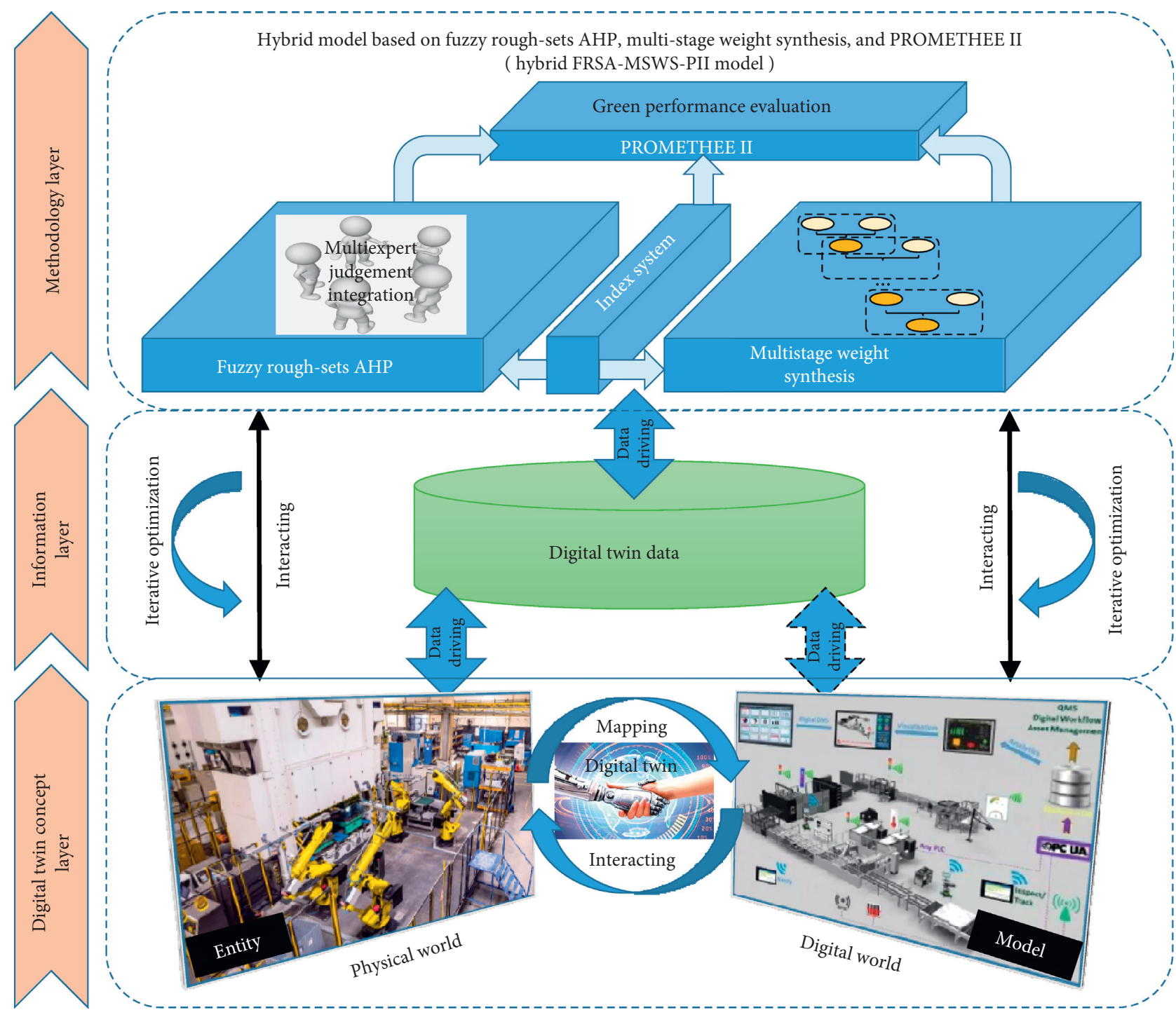

FIGURE 1: Green performance evaluation framework of intelligent manufacturing driven by digital twin.

degenerates into a triangular fuzzy number; when $\alpha=\chi=\delta=\beta, \tilde{a}$ degenerates into a real number.

The graph of function $f_{\tilde{a}}(x)$ is shown in Figure 2 .

The TFN is characterized by specific arithmetic operations that differ from those dealing with typical real numbers. The arithmetic operations between two TFNs $\tilde{a}_{1}=\left(\alpha_{1}, \chi_{1}, \delta_{1}, \beta_{1}\right)$ and $\tilde{a}_{2}=\left(\alpha_{2}, \chi_{2}, \delta_{2}, \beta_{2}\right)\left(\alpha_{1}, \chi_{1}, \delta_{1}, \beta_{1}, \alpha_{2}\right.$, $\left.\chi_{2}, \delta_{2}, \beta_{2} \in R^{+}, \lambda>0\right)$ are carried out using the following expressions:

(1) Addition of two TFNs " $\oplus$ ":

$$
\widetilde{a}_{1} \oplus \widetilde{a}_{2}=\left(\alpha_{1}+\alpha_{2}, \chi_{1}+\chi_{2}, \delta_{1}+\delta_{2}, \beta_{1}+\beta_{2}\right) .
$$

(2) Multiplication of two TFNs " $\otimes$ ":

$$
\widetilde{a}_{1} \otimes \widetilde{a}_{2}=\left(\alpha_{1} \cdot \alpha_{2}, \chi_{1} \cdot \chi_{2}, \delta_{1} \cdot \delta_{2}, \beta_{1} \cdot \beta_{2}\right) \text {. }
$$

(3) Multiplication of a real number and a TFN “ $\otimes$ ":

$$
\lambda \otimes \tilde{a}_{1}=\left(\lambda \cdot \alpha_{1}, \lambda \cdot \chi_{1}, \lambda \cdot \delta_{1}, \lambda \cdot \beta_{1}\right) .
$$

(4) Reciprocal of a TFN “-1":

$$
\left(\widetilde{a}_{1}\right)^{-1}=\left(\beta_{1}^{-1}, \delta_{1}^{-1}, \chi_{1}^{-1}, \alpha_{1}^{-1}\right)
$$

(5) Division of two TFNs "/":

$$
\frac{\widetilde{a}_{1}}{\tilde{a}_{2}}=\left(\frac{\alpha_{1}}{\beta_{2}}, \frac{\chi_{1}}{\delta_{2}}, \frac{\delta_{1}}{\chi_{2}}, \frac{\beta_{1}}{\alpha_{2}}\right) .
$$

(6) Barycenter of a TFN “๑”:

$$
\odot \widetilde{a}_{1}=\frac{\left(\delta_{1}^{2}+{\beta_{1}}^{2}-\alpha_{1}^{2}-\chi_{1}^{2}\right)+\left(\delta_{1} \cdot \beta_{1}-\alpha_{1} \cdot \chi_{1}\right)}{3\left(\delta_{1}+\beta_{1}-\alpha_{1}-\chi_{1}\right)} .
$$




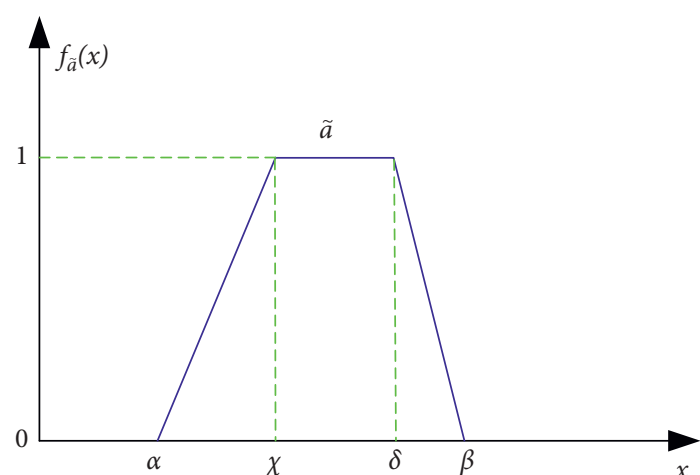

FIGURE 2: The membership function graph of triangular fuzzy number.

On the basis of the membership function of trapezoid fuzzy number shown by formula (2), a real number $a$ can be converted to trapezoid fuzzy number $\widetilde{a}[27,28]$. For example, $\widetilde{2}=(1,3 / 2,5 / 2,3)$. For trapezoid fuzzy number $\widetilde{a}$, its membership function $f_{\widetilde{a}}(x)$ is shown in Figure 3 . The commonly used nine-level scale assessment comments are extremely superior (ES), strongly superior (SS), obviously superior (OS), weakly superior (WS), equal (E), weakly inferior (WI), obviously inferior (OI), strongly inferior (SI), and extremely inferior (EI). The corresponding assessment values are $9,7,5,3,1,1 / 3,1 / 5,1 / 7$, and $1 / 9$ in order. The commonly used nine-level scale assessment comments and corresponding assessment values are converted to the trapezoid fuzzy number form as ES: $\widetilde{9} / \widetilde{1}$, SS: $\widetilde{8} / \widetilde{2}$, OS: $\widetilde{7} / \widetilde{3}$, WS: $\widetilde{6} / \widetilde{4}$, E: $\widetilde{5} / \widetilde{5}$, WI: $\widetilde{4} / \widetilde{6}$, OI: $\widetilde{3} / \widetilde{7}$, SI: $\tilde{2} / \widetilde{8}$, and EI: $\widetilde{1} / \widetilde{9}$. The membership functions of nine-level trapezoid fuzzy number scales are shown in Figure 4.

According to the arithmetic rules of trapezoid fuzzy number shown by formulas (3)-(8), the trapezoid fuzzy number values of nine-level scales are shown in Table 1.

3.1.2. Rough Approximation Set (RAS) and Rough Boundary Interval (RBI). According to rough-sets theory, the definitions of RAS and RBI are given as follows:

(1) Rough approximation set (RAS).

The domain $\varphi$ which is a nonempty finite set contains all objects. All objects in $\varphi$ belong to $n$ divisions, i.e., $D_{1}, D_{2}, \ldots, D_{n}$. The set of divisions in $\varphi$ is as follows:

$$
D=\left\{D_{1}, D_{2}, \ldots, D_{n}\right\} .
$$

Here, $D_{1}, D_{2}, \ldots, D_{n}$ have an order relationship as $D_{1}<D_{2}<\ldots<D_{n}$.

For a division $D_{w}(1 \leq w \leq n)$, its upper RAS (URAS) is defined as follows:

$$
\operatorname{URAS}\left(S_{w}\right)=\left\{Y \in K \mid K \in D \wedge K \geq D_{w}\right\} .
$$

And its lower RAS (LRAS) is defined as follows:

$$
\operatorname{LRAS}\left(S_{w}\right)=\left\{Y \in K \mid K \in D \wedge K \leq D_{w}\right\}
$$

where $Y$ is any object in $\varphi$.

(2) Rough boundary interval (RBI).

The mathematical characteristics of division $S_{w}$ can be embodied by its RBI, which is composed of lower rough limit (LRL) and upper rough limit (URL). So, RBI of $S_{w}$ is defined as follows:

$$
\operatorname{RBI}\left(S_{w}\right)=\left[\operatorname{LRL}\left(S_{w}\right), \operatorname{URL}\left(S_{w}\right)\right] .
$$

$\operatorname{LRL}\left(S_{w}\right)$ and $\operatorname{URL}\left(S_{w}\right)$ are expressed as follows:

$$
\begin{aligned}
& \operatorname{LRL}\left(S_{w}\right)=\frac{1}{\operatorname{Num}\left(\operatorname{LRAS}\left(S_{w}\right)\right)} \sum_{Y \in \operatorname{LRAS}\left(S_{w}\right)} Y, \\
& \operatorname{URL}\left(S_{w}\right)=\frac{1}{\operatorname{Num}\left(\operatorname{URAS}\left(S_{w}\right)\right)} \sum_{Y \in \operatorname{URAS}\left(S_{w}\right)} Y,
\end{aligned}
$$

where $\operatorname{Num}\left(\operatorname{LRAS}\left(S_{w}\right)\right)$ and $\operatorname{Num}\left(\operatorname{URAS}\left(S_{w}\right)\right)$ are the numbers of objects contained in the LRAS and URAS of $S_{w}$, respectively.

The arithmetic operations between two RBIs $\operatorname{RBI}\left(S_{w}\right)=$ $\left[\operatorname{LRL}\left(S_{w}\right), \operatorname{URL}\left(S_{w}\right)\right]$ and $\operatorname{RBI}\left(S_{u}\right)=\left[\operatorname{LRL}\left(S_{u}\right), \operatorname{URL}\left(S_{u}\right)\right]$ $\left(\operatorname{LRL}\left(S_{w}\right), \operatorname{URL}\left(S_{w}\right), \operatorname{LRL}\left(S_{u}\right)\right.$, and $\left.\operatorname{URL}\left(S_{u}\right) \in R^{+}, \lambda>0\right)$ are carried out using the following expressions:

(1) Addition of two RBIs " $\oplus$ ":

$\operatorname{RBI}\left(S_{w}\right) \oplus \operatorname{RBI}\left(S_{u}\right)=\left[\operatorname{LRL}\left(S_{w}\right)+\operatorname{LRL}\left(S_{u}\right), \operatorname{URL}\left(S_{w}\right)+\operatorname{URL}\left(S_{u}\right)\right]$.

(2) Multiplication of two RBIs “ $\otimes$ ":

$\operatorname{RBI}\left(S_{w}\right) \otimes \operatorname{RBI}\left(S_{u}\right)=\left[\operatorname{LRL}\left(S_{w}\right) \cdot \operatorname{LRL}\left(S_{u}\right), \operatorname{URL}\left(S_{w}\right) \cdot \operatorname{URL}\left(S_{u}\right)\right]$

(3) Multiplication of a real number and an RBI " $\otimes$ ":

$$
\lambda \otimes \operatorname{RBI}\left(S_{w}\right)=\left[\lambda \cdot \operatorname{LRL}\left(S_{w}\right), \lambda \cdot \operatorname{URL}\left(S_{w}\right)\right] .
$$

3.2. Evaluation Index System. Considering the typical environmental problems and the special influence of main stakeholders of intelligent manufacturing, the index system of green performance evaluation of intelligent manufacturing is constructed through the summary of the existing research, as shown in Figure 5. By integrating the target, dimension, and index of the green performance evaluation of intelligent manufacturing, the index system in this paper mainly constructs the three-level standardized framework.

In Figure 5, the target level is green performance evaluation of intelligent manufacturing; the dimension level has three elements: general environmental effect (dimension 1), social effect on employees (dimension 2), and social effect on users (dimension 3); the index level has nine indexes. 


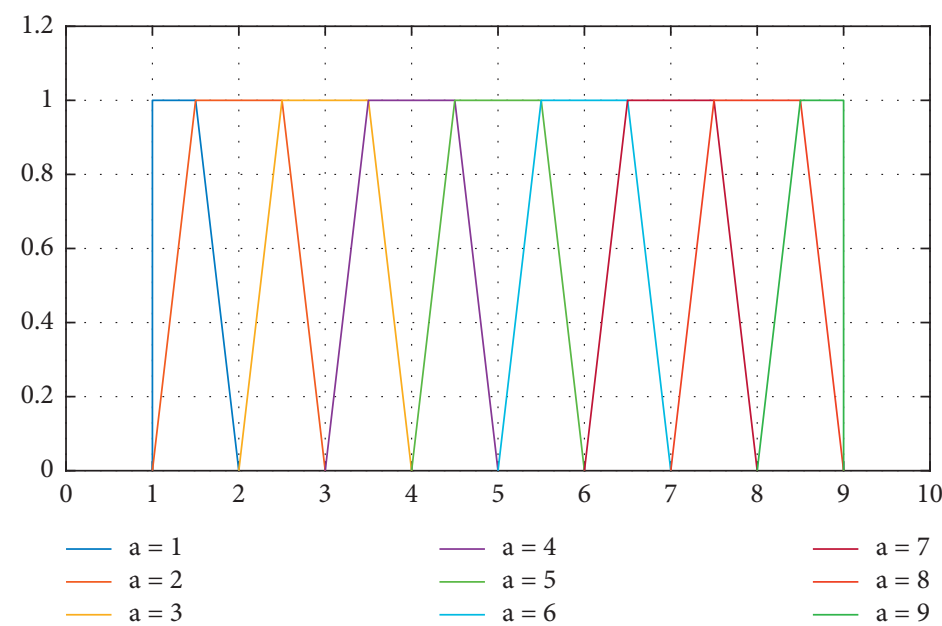

Figure 3: Membership functions of trapezoid fuzzy numbers $\tilde{a}(a=1-9)$.

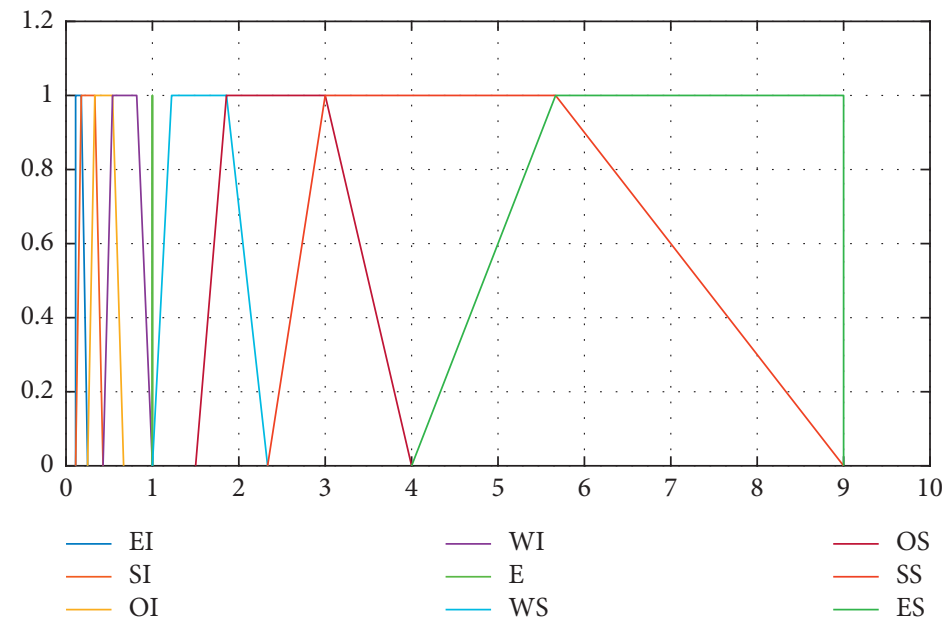

FIgUre 4: Membership functions of nine-level trapezoid fuzzy number scales (EI-ES).

Table 1: The trapezoid fuzzy number values of nine-level scales.

\begin{tabular}{lc}
\hline Nine-level scale & Trapezoid fuzzy number value \\
\hline EI & $(0.1111,0.1111,0.1765,0.2500)$ \\
SI & $(0.1111,0.1765,0.3333,0.4286)$ \\
OI & $(0.2500,0.3333,0.5385,0.6667)$ \\
WI & $(0.4286,0.5385,0.8182,1.0000)$ \\
E & $(1.0000,1.0000,1.0000,1.0000)$ \\
WS & $(1.0000,1.2222,1.8571,2.3333)$ \\
OS & $(1.5000,1.8571,3.0000,4.0000)$ \\
SS & $(2.3333,3.0000,5.6667,9.0000)$ \\
ES & $(4.0000,5.6667,9.0000,9.0000)$ \\
\hline
\end{tabular}

Furthermore, in the index level, exhaustion of resources and energy (index 1), destruction of ecological environment (index 2), and hazards to human health (index 3) belong to dimension 1; physical health effects (index 4), mental health effects (index 5), and impact on employee development (index 6) belong to dimension 2; physical health effects

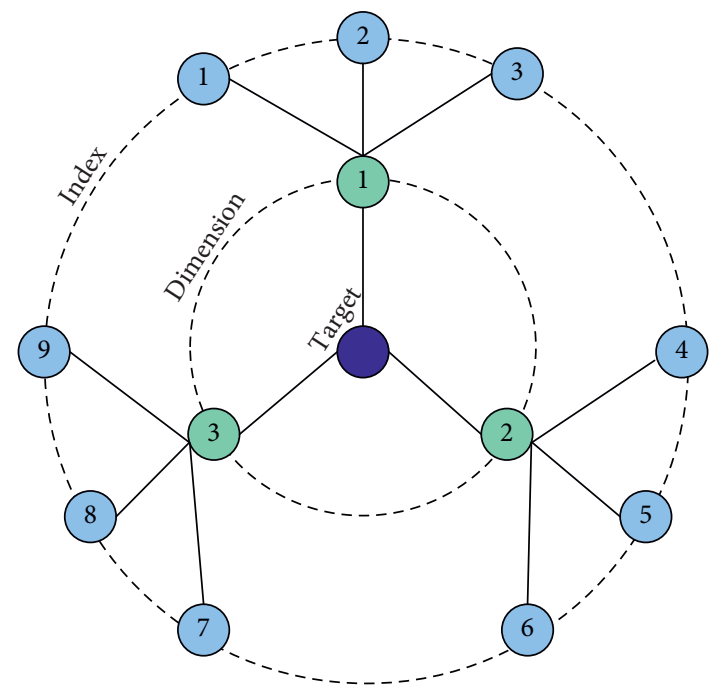

FIgURE 5: Three-level standardized framework for the index system. 
(index 7), mental health effects (index 8), and impact on user development (index 9) belong to dimension 1 .

3.3. The Process of Proposed Hybrid Model. This paper presents a digital twin driven green performance evaluation methodology of intelligent manufacturing by introducing the hybrid model (FRSA-MSWS-PII), as shown in Figure 6. Fuzzy numbers are used to deal with uncertainty of expert judgment in the group decision-making process, while RBI is used to integrate the judgments of multiple experts. Phase 1 includes the expert judgment of assessment index value by applying the fuzzy rough-sets AHP model, which results in the creation of input data required for the multistage weight synthesis model (phase 2) and PROMETHEE II model (phase 3). In phase 2, the multiple objective weights are based on the assessment index values from phase 1, while the multiple subjective weights are based on experts' judgment about the importance of assessment index. The output data of phase 2 are the final synthesized weights which are the input data of phase 3 .

The FRSA-MSWS-PII model, which is the subject matter of this paper, represents a novel approach for dealing with uncertainty in green performance evaluation of intelligent manufacturing based on fuzzy rough-sets AHP, multistage weight synthesis, and PROMETHEE II. For defining the final rank of intelligent manufacturing project alternatives, the FRSA-MSWS-PII method is used. The following three sections deal with the algorithms for the FRSA-MSWS-PII model.

3.3.1. Multiexpert Judgment Integration Based on Fuzzy Rough-Sets AHP. To achieve multiexpert judgment integration, there are two preconditions: (1) there are $N$ indexes: index 1 , index $2, \ldots$, index $N$, which constitute the index set is $I$. Here, $N=9$ and index 1 , index $2, \ldots$, index $N$ represent the indexes shown in Figure 5. (2) There are $q$ experts to assess the sustainable performance of $l$ intelligent manufacturing project alternatives. As shown in Figure 6, the fuzzy rough-sets AHP for multiexpert judgment integration, which is phase 1 of the hybrid model, is to obtain the index value of intelligent manufacturing project alternatives. Its process is as follows.

Experts judge the performance of all intelligent manufacturing project alternatives on any index based on their experiences and wisdom. On index $t(t=1,2, \ldots, N)$, the fuzzy reciprocal judgment matrix given by expert $k$ $(k=1,2, \ldots, q)$ is as follows:

$$
\widetilde{\Phi}^{k, t}=\left[\begin{array}{cccc}
\widetilde{\phi}_{1,1}^{k, t} & \widetilde{\phi}_{1,2}^{k, t} & \cdots & \widetilde{\phi}_{1, l}^{k, t} \\
\widetilde{\phi}_{2, t}^{k, t} & \widetilde{\phi}_{2,2}^{k, t} & \cdots & \widetilde{\phi}_{2, l}^{k, t} \\
\vdots & \vdots & & \vdots \\
\widetilde{\phi}_{l, 1}^{k, t} & \tilde{\phi}_{l, 2}^{k, t} & \cdots & \widetilde{\phi}_{l, l}^{k, t}
\end{array}\right],
$$

where $\widetilde{\phi}_{i, j}^{k, t}$ is the fuzzy score of intelligent manufacturing project alternative $i$ relative to intelligent manufacturing project alternative $j$ given by expert $k$ on index $t$ and $\widetilde{\phi}_{j, i}^{k, t}=1 / \widetilde{\phi}_{i, j}^{k, t}$.

According to the table, the set of the nine-level scales is $\mathrm{SCA}=\{\mathrm{EI}, \mathrm{SI}, \mathrm{OI}, \mathrm{WI}, E, \mathrm{WS}, \mathrm{OS}, \mathrm{SS}, \mathrm{ES}\}$ and the set of trapezoid fuzzy number values of nine-level scales is TFN$\mathrm{SCA}=\{(0.1111,0.1111,0.1765,0.2500),(0.1111,0.1765$, $0.3333,0.4286),(0.2500,0.3333,0.5385,0.6667),(0.4286$, $0.5385,0.8182,1.0000),(1.0000,1.0000,1.0000,1.0000)$, $(1.0000,1.2222,1.8571,2.3333),(1.0000,1.2222,1.8571$, 2.3333), (2.3333, 3.0000, 5.6667, 9.0000), (4.0000, 5.6667, $9.0000,9.0000)\}$.

From the perspective of judgment comment, $\widetilde{\phi}_{i, j}^{k, t} \in \mathrm{SCA}$, which represents the evaluation of performance of intelligent manufacturing project alternative $i$ relative to intelligent manufacturing project alternative $j$ given by expert $k$ on index $t$, while from the perspective of judgment value, $\widetilde{\phi}_{i, j}^{k, t} \in$ TFN-SCA, which is a trapezoid fuzzy number, and can be represented as follows:

$$
\tilde{\phi}_{i, j}^{k, t}=\left(\alpha_{i, j}^{k, t}, \chi_{i, j}^{k, t}, \delta_{i, j}^{k, t}, \beta_{i, j}^{k, t}\right) .
$$

Especially, when $i=j, \widetilde{\phi}_{i, j}^{k, t}=(1,1,1,1)$.

Consistency inspection is carried out after all experts finish their judgment. If any fuzzy reciprocal judgment matrix fails to pass the consistency inspection, the corresponding expert should adjust his judgment matrix. The basic idea of consistency inspection for fuzzy reciprocal judgment matrix is using formula (8) to convert trapezoid fuzzy number to real number, and then, fuzzy reciprocal judgment matrix $\widetilde{\Phi}^{k, t}$ could be transformed into general judgment matrix $\widetilde{\Phi}^{k, t}$ as follows:

$$
\Phi^{k, t}=\left[\begin{array}{cccc}
\phi_{l, 1}^{k, t} & \phi_{1,2}^{k, t} & \cdots & \phi_{1, l}^{k, t} \\
\phi_{2,1}^{k, t} & \phi_{2,2}^{k, t} & \cdots & \phi_{2, l}^{k, t} \\
\vdots & \vdots & & \vdots \\
\phi_{l, 1}^{k, t} & \phi_{l, 2}^{k, t} & \cdots & \phi_{l, l}^{k, t}
\end{array}\right] .
$$

Consistency index (CI) of $\Phi^{k, t}$ is represented as follows:

$$
\mathrm{CI}^{k, t}=\frac{\left(\lambda_{\max }\right)^{k, t}-l}{l-1},
$$

where $\left(\lambda_{\max }\right)^{k, t}$ is the maximum eigenvalue of $\Phi^{k, t}$.

Usually, consistency ratio (CR) is used to evaluate the consistency of reciprocal judgment matrix. For $\Phi^{k, t}$, its CR is represented as follows:

$$
\mathrm{CR}^{k, t}=\frac{\mathrm{CI}^{k, t}}{\mathrm{RI}^{k, t}},
$$

where $\mathrm{RI}^{k, t}$ is a random index (RI) that depends on the dimension $l$ of $\Phi^{k, t}$. The specific value of RI is shown in Table 2.

When $\mathrm{CR}^{k, t}>0.1$, the judgment logic of expert $k$ on index $I_{t}$ is inconsistent and $\Phi^{k, t}$ fails to pass the consistency inspection. As a result, expert $k$ should adjust his judgment process and give a new judgment matrix.

Ulteriorly, the group judgment matrix is constructed as follows: 


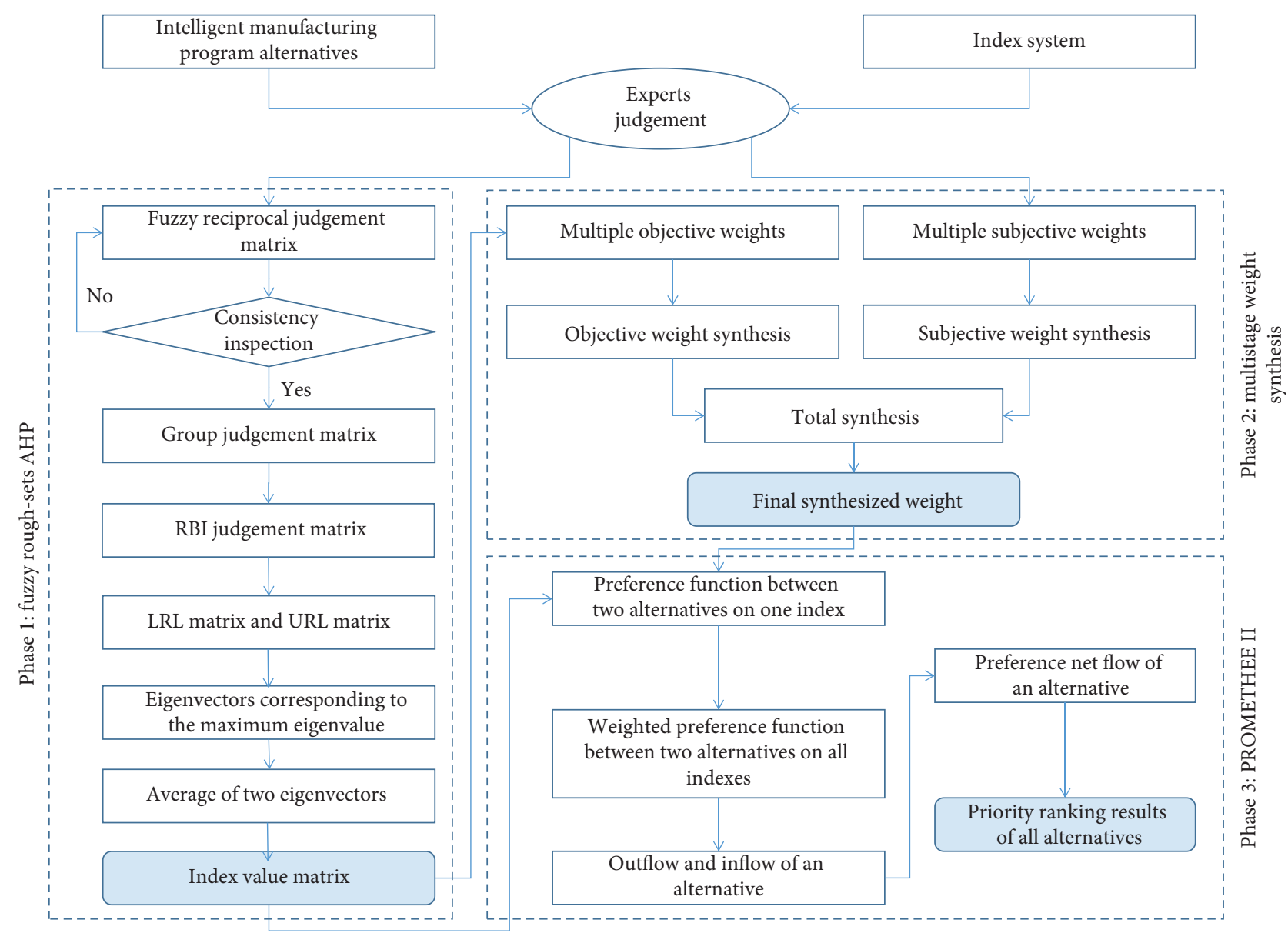

Figure 6: The process of the proposed FRSA-MSWS-PII model.

TABle 2: The specific value of RI.

\begin{tabular}{lccccccccc}
\hline Dimension $l$ & 1 & 2 & 3 & 4 & 5 & 6 & 7 & 8 & 9 \\
\hline RI & 0.00 & 0.00 & 0.58 & 0.90 & 1.12 & 1.24 & 1.32 & 1.41 & 1.45 \\
\hline
\end{tabular}

$$
\widetilde{\Theta}^{t}=\left[\begin{array}{cccc}
\tilde{\rho}_{1,1}^{t} & \tilde{\rho}_{1,2}^{t} & \cdots & \widetilde{\rho}_{1, l}^{t} \\
\tilde{\rho}_{2,1}^{t} & \tilde{\rho}_{2,2}^{t} & \cdots & \widetilde{\rho}_{2, l}^{t} \\
\vdots & \vdots & & \vdots \\
\widetilde{\rho}_{l, 1}^{t} & \widetilde{\rho}_{l, 2}^{t} & \cdots & \tilde{\rho}_{l, l}^{t}
\end{array}\right] .
$$

Element $\widetilde{\rho}_{i, j}^{t}$ is a set, which can be represented as follows:

$$
\tilde{\rho}_{i, j}^{t}=\left\{\widetilde{\phi}_{i, j}^{1, t}, \widetilde{\phi}_{i, j}^{2, t}, \ldots, \widetilde{\phi}_{i, j}^{q, t}\right\},
$$

In $\widetilde{\rho}_{i, j}^{t}$, the fuzzy RBI of $\widetilde{\phi}_{i, j}^{k, t}$ is obtained according to related concepts given by formulas (8)-(13) as follows:

$$
\begin{aligned}
& \operatorname{RBI}\left(\tilde{\phi}_{i, j}^{k, t}\right)=\left[\operatorname{LRL}\left(\tilde{\phi}_{i, j}^{k, t}\right), \operatorname{URL}\left(\tilde{\phi}_{i, j}^{k, t}\right)\right] \\
& =\left[\frac{1}{\operatorname{Num}\left(\operatorname{LRAS}\left(\widetilde{\phi}_{i, j}^{k, t}\right)\right)} \sum_{\substack{Y \in \widetilde{\rho}_{i, j}^{t} \\
\widetilde{\phi}_{i, t}}} Y, \frac{1}{\operatorname{Num}\left(\operatorname{URAS}\left(\widetilde{\phi}_{i, j}^{k, t}\right)\right)} \sum_{\substack{Y \in \widetilde{\rho}_{i, j}^{t} \\
\widetilde{\phi}_{i, t} \\
Y \geq \hat{\phi}_{i, j}}} Y\right] .
\end{aligned}
$$


Based on the arithmetic operation rule of RBI shown by formulas (16)-(18), RBI of $\tilde{\rho}_{i, j}^{t}$ is obtained as follows:

$$
\begin{aligned}
\operatorname{RBI}\left(\tilde{\rho}_{i, j}^{t}\right) & =\left[\operatorname{LRL}\left(\tilde{\rho}_{i, j}^{t}\right), \operatorname{URL}\left(\tilde{\rho}_{i, j}^{t}\right)\right] \\
& =\left[\frac{1}{q} \sum_{k=1}^{q} \operatorname{LRL}\left(\widetilde{\phi}_{i, j}^{k, t}\right), \frac{1}{q} \sum_{k=1}^{q} \operatorname{URL}\left(\widetilde{\phi}_{i, j}^{k, t}\right)\right] .
\end{aligned}
$$

Then, the RBI judgment matrix is constructed as follows:

$$
\tilde{\Lambda}^{t}=\left[\begin{array}{cccc}
\operatorname{RBI}\left(\widetilde{\rho}_{1,1}^{t}\right) & \operatorname{RBI}\left(\widetilde{\rho}_{1,2}^{t}\right) & \cdots & \operatorname{RBI}\left(\widetilde{\rho}_{1, l}^{t}\right) \\
\operatorname{RBI}\left(\widetilde{\rho}_{2,1}^{t}\right) & \operatorname{RBI}\left(\widetilde{\rho}_{2,2}^{t}\right) & \cdots & \operatorname{RBI}\left(\widetilde{\rho}_{2, l}^{t}\right) \\
\vdots & \vdots & & \vdots \\
\operatorname{RBI}\left(\widetilde{\rho}_{l, 1}^{t}\right) & \operatorname{RBI}\left(\widetilde{\rho}_{l, 2}^{t}\right) & \cdots & \operatorname{RBI}\left(\widetilde{\rho}_{l, l}^{t}\right)
\end{array}\right] .
$$

$\widetilde{\Lambda}^{t}$ is decomposed into LRL matrix and URL matrix as follows:

$$
\begin{gathered}
\widetilde{\Lambda}_{\mathrm{LRL}}^{t}=\left[\begin{array}{cccc}
\operatorname{LRL}\left(\tilde{\rho}_{1,1}^{t}\right) & \operatorname{LRL}\left(\tilde{\rho}_{1,2}^{t}\right) & \cdots & \operatorname{LRL}\left(\tilde{\rho}_{1, l}^{t}\right) \\
\operatorname{LRL}\left(\tilde{\rho}_{2,1}^{t}\right) & \operatorname{LRL}\left(\tilde{\rho}_{2,2}^{t}\right) & \cdots & \operatorname{LRL}\left(\tilde{\rho}_{2, l}^{t}\right) \\
\vdots & \vdots & & \vdots \\
\operatorname{LRL}\left(\tilde{\rho}_{l, 1}^{t}\right) & \operatorname{LRL}\left(\tilde{\rho}_{l, 2}^{t}\right) & \cdots & \operatorname{LRL}\left(\tilde{\rho}_{l, l}^{t}\right)
\end{array}\right], \\
\tilde{\Lambda}_{\mathrm{URL}}^{t}=\left[\begin{array}{cccc}
\operatorname{URL}\left(\tilde{\rho}_{1,1}^{t}\right) & \mathrm{URL}\left(\tilde{\rho}_{1,2}^{t}\right) & \cdots & \operatorname{URL}\left(\tilde{\rho}_{1, l}^{t}\right) \\
\operatorname{URL}\left(\tilde{\rho}_{2,1}^{t}\right) & \mathrm{URL}\left(\tilde{\rho}_{2,2}^{t}\right) & \cdots & \operatorname{URL}\left(\tilde{\rho}_{2, l}^{t}\right) \\
\vdots & \vdots & & \vdots \\
\operatorname{URL}\left(\tilde{\rho}_{l, 1}^{t}\right) & \operatorname{URL}\left(\tilde{\rho}_{l, 2}^{t}\right) & \cdots & \operatorname{URL}\left(\tilde{\rho}_{l, l}^{t}\right)
\end{array}\right] .
\end{gathered}
$$

Based on the barycenter operation shown by formula (8), $\tilde{\Lambda}_{\mathrm{LRL}}^{t}$ and $\tilde{\Lambda}_{\mathrm{URL}}^{t}$ are converted into real number forms: $\Lambda_{\mathrm{LRL}}^{t}$ and $\Lambda_{\mathrm{URL}}^{t}$. The eigenvectors of $\Lambda_{\mathrm{LRL}}^{t}$ and $\Lambda_{\mathrm{URL}}^{t}$ corresponding to the maximum eigenvalue are obtained, respectively, as follows:

$$
\begin{gathered}
\operatorname{Eig}\left(\Lambda_{\mathrm{LRL}}^{t}\right)=\left[\operatorname{Eig}_{1}\left(\Lambda_{\mathrm{LRL}}^{t}\right), \operatorname{Eig}_{2}\left(\Lambda_{\mathrm{LRL}}^{t}\right), \ldots, \operatorname{Eig}_{l}\left(\Lambda_{\mathrm{LRL}}^{t}\right)\right] \\
\operatorname{Eig}\left(\Lambda_{\mathrm{URL}}^{t}\right)=\left[\operatorname{Eig}_{1}\left(\Lambda_{\mathrm{URL}}^{t}\right), \operatorname{Eig}_{2}\left(\Lambda_{\mathrm{URL}}^{t}\right), \ldots, \operatorname{Eig}_{l}\left(\Lambda_{\mathrm{URL}}^{t}\right)\right] .
\end{gathered}
$$

After averaging the two eigenvectors shown in formulas (29) and (30), an average vector is obtained as follows:

$$
\operatorname{Eig}\left(\Lambda_{\text {Aver }}^{t}\right)=\left[\operatorname{Eig}_{1}\left(\Lambda_{\text {Aver }}^{t}\right), \operatorname{Eig}_{2}\left(\Lambda_{\text {Aver }}^{t}\right), \ldots, \operatorname{Eig}_{l}\left(\Lambda_{\text {Aver }}^{t}\right)\right] \text {, }
$$

where $\operatorname{Eig}_{i}\left(\Lambda_{\text {Aver }}^{t}\right)=(1 / 2)\left(\operatorname{Eig}_{i}\left(\Lambda_{\text {LRL }}^{t}\right)+\operatorname{Eig}_{i}\left(\Lambda_{\mathrm{URL}}^{t}\right)\right)$.

The index value of alternate intelligent manufacturing project $i$ on index $t$ is obtained as $\operatorname{Eig}_{i}\left(\Lambda_{\text {Aver }}^{t}\right)$. After solving the index values of $l$ intelligent manufacturing project alternates on other indexes by similar way, the index value matrix of $l$ intelligent manufacturing project alternates on all indexes is obtained as $X=\left[x_{i, t}\right]_{l \times N}$, where $x_{i, t}=\operatorname{Eig}_{i}\left(\Lambda_{\text {Aver }}^{t}\right)$.

3.3.2. Multistage Weight Synthesis. Solving index weight is the key step of comprehensive decision of green performance evaluation of intelligent manufacturing. Generally, there are three methods to determine index weight: subjective weight method, objective weight method, and synthesis weight method. The subjective weight method generally uses the knowledge and experience of experts, but the evaluation results are not scientific because of subjectivity; the objective weight method determines the weight according to the degree of difference between indexes but often ignores the importance of the indexes themselves; the synthesis weight method is usually composed of a variety of subjective and objective weight methods, which can offset the shortcomings of different weight methods.

In the aspect of index weight solving for green performance evaluation of intelligent manufacturing, in order to avoid the instability of assessment result caused by single weight and make the weight setting of assessment index more fair and reasonable, a multistage synthesis weight method is proposed to solve index weight. The proposed method has three stages of weight synthesis, and there are several substages in each stage of weight synthesis.

As shown in Figure 7, the proposed multistage weight synthesis method has a detailed process as follows:

(1) Stage 1: subjective weight synthesis.

Subjective weight methods mainly include complex networks method, ANP method, and Delphi method. The principle and solution process of these methods are as follows:

(i) Complex networks method. By complex networks method, the determination of index weight is regarded as the evaluation of node importance in complex networks. The index can be treated as node in complex networks, and the network attributes (degree centrality, betweenness centrality, and closeness centrality) of a node describe its importance in the network from different aspects (local attribute, propagation attribute, and global attribute). Therefore, we use expert evaluation to determine whether there is a relationship between two indexes, regardless of the direction of the relationship. Based on this, an undirected network with index as node is established. Then, the degree centrality, betweenness centrality, and closeness centrality of each node are computed. Taking the network attributes of index as criterion, the net flow of each index is calculated by the Preference Ranking Organization Method for Enrichment Evaluations II (PROMETHEE II) method. The relative net flow of an index is obtained by calculating the relative difference between its net flow and the minimum net flow, and then, the relative net flow of all indexes is normalized to get the index weight. The process of complex networks method is shown in Figure 8.

(ii) ANP method. The ANP structure of determining the subjective weight of green performance evaluation of intelligent manufacturing is 


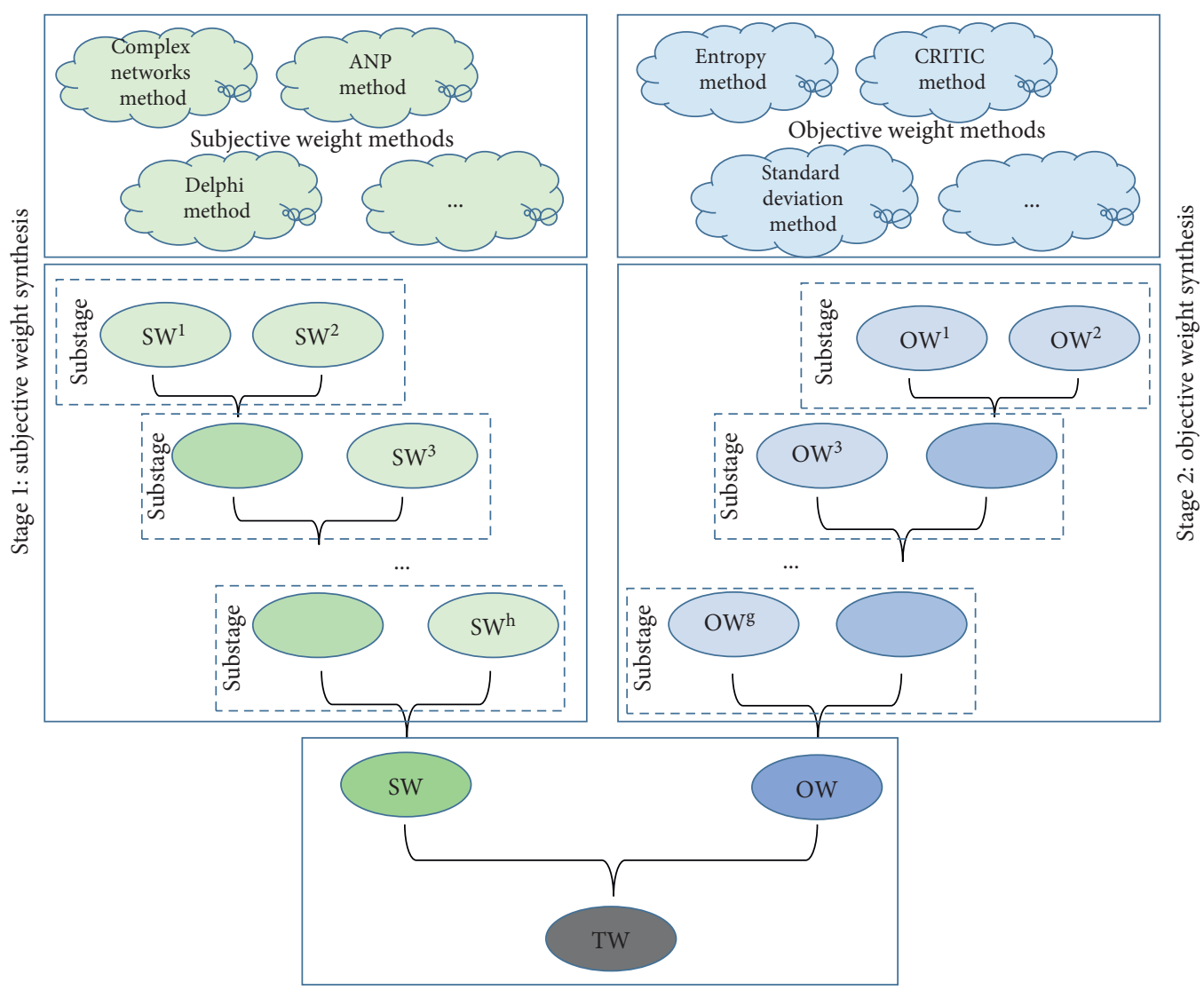

Stage 3: total synthesis

Figure 7: The process of multistage weight synthesis.

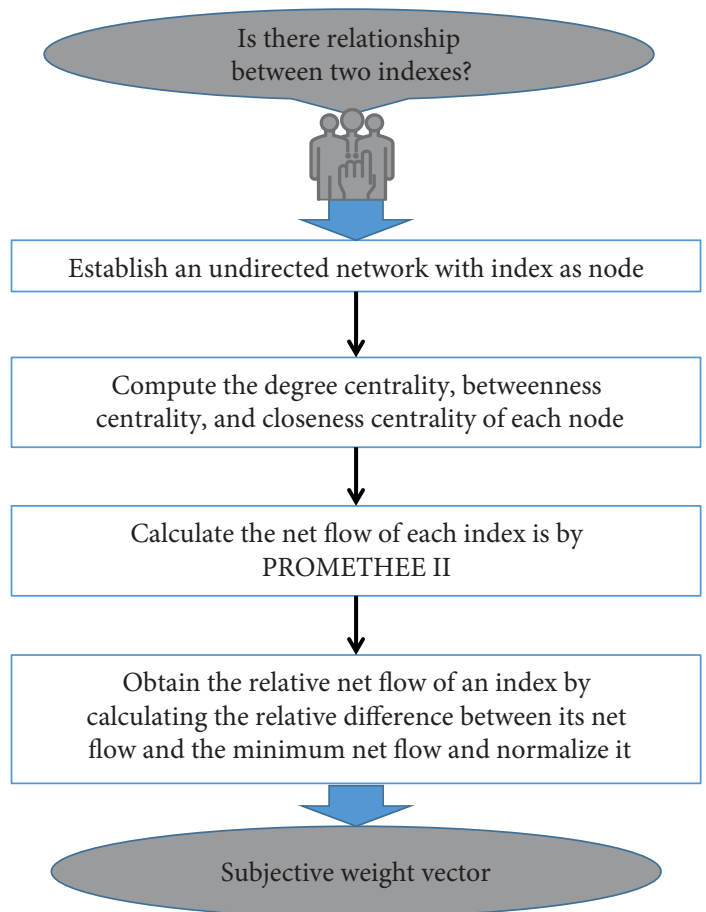

FIGURE 8: The process of obtaining subjective weight by complex networks method. 
set up, as shown in Figure 9. The control layer only has one element: the overall goal (green performance evaluation of intelligent manufacturing), and the network layer has three element groups corresponding to three performance dimensions. Each element group affects each other and contains different elements. The elements in the same element group also affect each other. Based on the experts' evaluation of the importance and influence among the indexes, the weights of the indexes are determined by the classical ANP method.

(iii) Delphi method. It usually relies on the knowledge, experience, and specialty of experts to score the indexes of the evaluation object separately and generally adopts the percentage grading system and then takes the average value of all experts' scores as the weight of the evaluation index. This method has convenient operation, easy investigation procedure, and simple calculation.

It is assumed that the subjective weight vectors obtained by $h$ different methods are as follows:

$$
\begin{aligned}
\mathrm{SW}^{1} & =\left[\mathrm{sw}_{1}^{1}, \mathrm{sw}_{2}^{1}, \ldots, \mathrm{sw}_{N}^{1}\right]^{\mathrm{T}}, \\
\mathrm{SW}^{2} & =\left[\mathrm{sw}_{1}^{2}, \mathrm{sw}_{2}^{2}, \ldots, \mathrm{sw}_{N}^{2}\right]^{\mathrm{T}}, \\
\ldots & \\
\mathrm{SW}^{h} & =\left[\mathrm{sw}_{1}^{h}, \mathrm{sw}_{2}^{h}, \ldots, \mathrm{sw}_{N}^{h}\right]^{\mathrm{T}} .
\end{aligned}
$$

In the subjective weight synthesis stage, there are $h-1$ substages, and each substage corresponds to a synthesis. Taking the synthesis of $\mathrm{SW}^{1}$ and $\mathrm{SW}^{2}$ as an example, their synthesized weight vector $\mathrm{SW}^{102}=\left[s w_{1}^{1 \circ 2}, s w_{2}^{1 \circ 2}, \ldots, s w_{N}^{1 \circ 2}\right]^{\mathrm{T}}$ is defined as follows:

$$
\mathrm{SW}^{102}=\tau_{1} \mathrm{SW}^{1}+\tau_{2} \mathrm{SW}^{2},
$$

where $\tau_{1}$ and $\tau_{2}$ are the synthesis coefficients corresponding to $\mathrm{SW}^{1}$ and $\mathrm{SW}^{2}$ and $\tau_{1} \geq 0, \tau_{2} \geq 0$, and $\tau_{1}+\tau_{2}=1$.

According to index value matrix $X=\left[x_{i, t}\right]_{l \times N}$, the weight contribution difference degree of $\mathrm{SW}^{1}$ and $\mathrm{SW}^{2}$ is defined as follows:

$$
\xi^{1 \circ 2}=\sum_{i=1}^{l} \sum_{t=1}^{N}\left(\tau_{1} \mathrm{sw}_{t}^{1} x_{i, t}-\tau_{2} \mathrm{sw}_{t}^{2} x_{i, t}\right)^{2} .
$$

Therefore, a weight synthesis optimization model is established to balance the weight contribution of SW ${ }^{1}$ and $\mathrm{SW}^{2}$ as follows:

$$
\begin{array}{ll}
\min & \xi^{102} \\
\text { s.t. } & \tau_{1} \geq 0, \tau_{2} \geq 0, \tau_{1}+\tau_{2}=1 .
\end{array}
$$

Two synthesis coefficients are solved as follows:

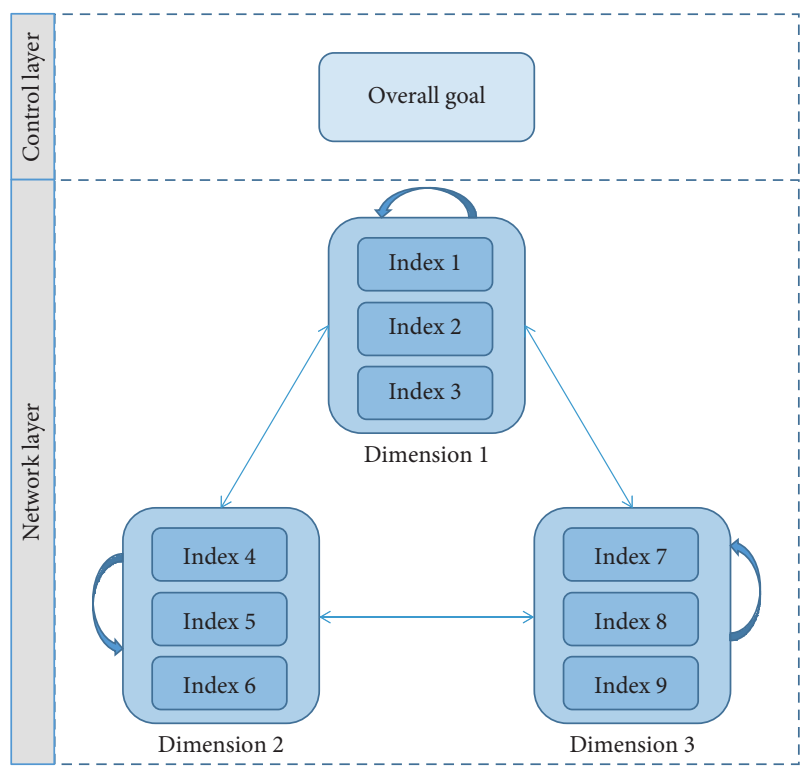

Figure 9: The ANP structure.

$$
\begin{aligned}
& \tau_{1}=\frac{\sum_{i=1}^{l} \sum_{t=1}^{N}\left(x_{i, t}\right)^{2} \mathrm{sw}_{t}^{2}\left(\mathrm{sw}_{t}^{1}+\mathrm{sw}_{t}^{2}\right)}{\sum_{i=1}^{l} \sum_{t=1}^{N}\left(x_{i, t}\right)^{2}\left(\mathrm{sw}_{t}^{1}+\mathrm{sw}_{t}^{2}\right)}, \\
& \tau_{2}=1-\tau_{1} .
\end{aligned}
$$

$\mathrm{SW}^{102}$ and $\mathrm{SW}^{3}$ are synthesized in the same way, and their synthesized weight vector is obtained as $\mathrm{SW}^{10203}$. According to the process of subjective weight synthesis stage shown in Figure 1, the synthesized subjective weight vector can be obtained in the end as follows:

$$
\mathrm{SW}^{102 \ldots \circ h}=\left[\mathrm{sw}_{1}^{1020 \ldots h}, \mathrm{Sw}_{2}^{1020 \ldots h}, \ldots, \mathrm{Sw}_{N}^{1020 \ldots h}\right]^{\mathrm{T}} .
$$

(2) Stage 2: objective weight synthesis.

Objective weight methods mainly include entropy method, CRITIC method, and standard deviation method. The principle and solution process of these methods are as follows:

(i) Entropy method. In information theory, entropy is a measure of uncertainty, which determines the weight according to the variation in index. Generally, the smaller the entropy of an index, the greater the variation degree in the index, the more the information it provides, and the greater its weight; on the contrary, the larger the entropy of an index, the smaller the variation degree of the index, the less information it provides, and the smaller its weight. Entropy method calculates the weight of an index based on its information quantity.

(ii) CRITIC method. Its basic idea is to comprehensively measure the weight of the index through the contrast intensity within the index and the conflict between the indexes. Contrast 
intensity is presented in the form of standard deviation, while conflict is determined by the correlation between indexes.

(iii) Standard deviation method. This method uses the standard deviation of an index to determine its weight. If an index has a larger standard deviation, which means that the index is more different in value, its weight will be larger. By normalizing the standard deviations of all indexes, the weights of indexes can be obtained. According to the process of objective weight synthesis stage shown in Figure 1, by the same way with the solving process of synthesized subjective weight vector, the synthesized objective weight vector also can be obtained in the end as follows:

$$
\mathrm{OW}^{1 \circ 2 \circ \ldots \circ \mathrm{g}}=\left[\mathrm{ow}_{1}^{1 \circ 2 \circ \ldots \circ \mathrm{g}}, \mathrm{ow}_{2}^{1 \circ 2 \circ \ldots \circ \mathrm{g}}, \ldots, \mathrm{ow}_{N}^{1 \circ 2 \circ \ldots \circ \mathrm{g}}\right]^{\mathrm{T}} .
$$

(3) Stage 3: total synthesis.

Under the premise of obtaining synthesized subjective weight $\mathrm{SW}^{1 \circ 2 \circ \ldots \circ h}$ and synthesized objective

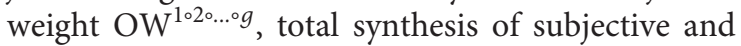
objective weight is carried out using the same weight synthesis optimization model shown by formula (35), and the vector $\mathrm{TW}=\left[\mathrm{tw}_{1}, \mathrm{tw}_{2}, \ldots, \mathrm{tw}_{N}\right]^{\mathrm{T}}$ is obtained as follows:

$$
\mathrm{TW}=\tau_{\mathrm{sw}} \mathrm{SW}^{1 \circ 2 \circ \ldots \circ h}+\tau_{\mathrm{ow}} \mathrm{OW}^{1 \circ 2 \circ \ldots \circ g},
$$

where $\tau_{\text {sw }}$ and $\tau_{\text {ow }}$ are the subjective synthesis coefficient and objective synthesis coefficient, and they are corresponding to $\mathrm{SW}^{1020 \ldots \circ h}$ and $\mathrm{OW}^{1020 \ldots \circ g}$, respectively. Here, $\tau_{\text {sw }} \geq 0, \tau_{\text {ow }} \geq 0$, and $\tau_{\text {sw }}+\tau_{\text {ow }}=1$.

3.3.3. Intelligent Manufacturing Project Evaluation by PROMETHEE II. Traditional object assessment methods include TOPSIS (Technique for Order Preference by Similarity to an Ideal Solution) [28], VIKOR (VlseKriterijumska Optimizacija I Kompromisnoresenje) [29], AHP, and other mixedmodel MCDM methods. These methods have decision compensation in the assessment and decision-making process; that is, the high value of one index can remedy the low value of other indexes. In this part, PROMETHEE II [30] is used to assess the green performance and sort several intelligent manufacturing projects. The core idea of this method is that the level is not lower than the relationship. By PROMETHEE II, the priority function is used to compare the intelligent manufacturing projects one by one to determine the priority sequence of all intelligent manufacturing projects, which can avoid the influence of decision compensation on the assessment results of intelligent manufacturing projects. This method fully considers the objective facts of the existence of the preference of the decision-maker, making the decision-making results more convincing.
In PROMETHEE II, there are many common criteria to determine the preference function. Compared with others, the Gaussian preference function has nonlinear characteristics, which is more in line with the actual decision-making environment. Therefore, this paper chooses the preference function in the form of Gaussian criteria. The index values of intelligent manufacturing projects $i$ and $m(i, m=1,2, \ldots, l$ and $i \neq m)$ in index $t$ are $x_{i, t}$ and $x_{m, t}$, respectively. On index $t$, the preference function of intelligent manufacturing project $i$ compared with intelligent manufacturing project $m$ is defined as follows:

$$
p_{t}(i, m)= \begin{cases}0, & x_{i, t}-x_{m, t} \leq 0, \\ 1-e^{-\left(x_{i, t}-x_{m, t}\right) 2 / 2 \eta^{2}}, & x_{i, t}-x_{m, t}>0\end{cases}
$$

where the value of parameter $\eta$ is 0.2 .

Under the condition of considering all indexes, the weighted preference degree of intelligent manufacturing project $i$ compared with intelligent manufacturing project $m$ is expressed as follows:

$$
p(i, m)=\sum_{t=1}^{N} w_{t} \cdot p_{t}(i, m) .
$$

The outflow $\Omega_{i}^{+}$and inflow $\Omega_{i}^{-}$of intelligent manufacturing project $i$ can be obtained as follows:

$$
\begin{aligned}
& \Omega_{i}^{+}=\sum_{m=1, m \neq i}^{l} p(i, m), \\
& \Omega_{i}^{-}=\sum_{m=1, m \neq i}^{l} p(m, i),
\end{aligned}
$$

where $p(m, i)$ represents the weighted preference degree of intelligent manufacturing project $m$ compared with intelligent manufacturing project $i$ under the condition of considering all indexes.

The degree of intelligent manufacturing project $i$ superior to other projects can be represented by outflow $\Omega_{i}^{+}$, and the degree of intelligent manufacturing project $i$ inferior to other projects can be represented by inflow $\Omega_{i}^{-}$. Therefore, the preference net flow of intelligent manufacturing project $i$ is represented as follows:

$$
\Omega_{i}=\Omega_{i}^{+}-\Omega_{i}^{-} .
$$

The net flow is the main basis for the PROMETHEE II method to measure the advantages and disadvantages of the intelligent manufacturing projects. The priority ranking results of all intelligent manufacturing projects can be obtained by comparing the net flow values.

\section{Case Study: Application of the FRSA-MSWS- PII Model for Green Performance Evaluation of Intelligent Manufacturing Project for an Air Conditioning Enterprise Driven by Digital Twin}

The remote operation and maintenance service project is a key component of the intelligent manufacturing strategy for an air conditioning enterprise. This section will evaluate the 
green performance of the remote operation and maintenance service project alternatives to obtain the optimal one from multiple alternatives. The enterprise has built the digital twin system of its intelligent manufacturing project, which can provide the digital twin data of whole life cycle for green performance evaluation. There are ten alternatives of intelligent manufacturing project of remote operation and maintenance service, which are Alter. 1, Alter. 2,..., Alter. 10. Three experts participate in the index value calculation of intelligent manufacturing project alternatives. For index 1, the fuzzy reciprocal assessment matrices given by three experts are $\widetilde{\Phi}^{1,1}=\left[\widetilde{\phi}_{i, j}^{1,1}\right]_{10 \times 10}, \quad \widetilde{\Phi}^{2,1}=\left[\widetilde{\phi}_{i, j}^{2,1}\right]_{10 \times 10}, \quad$ and $\widetilde{\Phi}^{3,1}=\left[\widetilde{\phi}_{i, j}^{3,1}\right]_{10 \times 10}$. Due to limited space and without losing generality, only $\widetilde{\Phi}^{1,1}$ is given as follows:

$$
\widetilde{\Phi}^{1,1}=\left[\begin{array}{cccccccccc}
E & \text { OS } & E & \text { WS } & \text { OS } & E & \text { ES } & \text { WS } & \text { OS } & E \\
\text { OI } & E & \text { OI } & \text { WI } & E & E & \text { SI } & \text { OI } & \text { WI } & \text { WI } \\
E & \text { OS } & E & \text { WS } & E & \text { OS } & \text { WS } & \text { SS } & E & \text { OS } \\
\text { WI } & \text { WS } & \text { WI } & E & \text { WS } & \text { OS } & E & \text { WS } & E & \text { SS } \\
\text { OI } & E & \text { OI } & \text { WI } & E & \text { EI } & E & \text { SI } & \text { WI } & \text { WI } \\
E & E & \text { OI } & \text { OI } & \text { ES } & E & E & \text { SI } & \text { SI } & \text { EI } \\
\text { EI } & \text { SS } & \text { WI } & E & \text { SS } & E & E & \text { SS } & \text { OS } & E \\
\text { WI } & \text { OS } & \text { SI } & \text { WI } & \text { SS } & \text { SS } & \text { SI } & E & \text { WI } & \text { WS } \\
\text { OI } & \text { WS } & E & E & \text { WS } & \text { SS } & \text { OI } & \text { WS } & E & \text { SI } \\
E & \text { WS } & \text { OI } & \text { SI } & \text { WS } & \text { ES } & E & \text { WI } & \text { SS } & E
\end{array}\right] .
$$

Through consistency inspection, three matrices $\widetilde{\Phi}^{1,1}$, $\widetilde{\Phi}^{2,1}$, and $\widetilde{\Phi}^{3,1}$ can pass the inspection. Then, the group judgment matrix $\widetilde{\Theta}^{1}=\left[\widetilde{\rho}_{i, j}^{1}\right]_{10 \times 10}$ is constructed based on $\widetilde{\Phi}^{1,1}, \widetilde{\Phi}^{2,1}$, and $\widetilde{\Phi}^{3,1}$ and $\widetilde{\rho}_{i, j}^{1}=\left\{\widetilde{\phi}_{i, j}^{1,1}, \widetilde{\phi}_{i, j}^{2,1}, \widetilde{\phi}_{i, j}^{3,1}\right\}$. For example, $\tilde{\rho}_{1,2}^{1}=\left\{\tilde{\phi}_{1,2}^{1,1}, \widetilde{\phi}_{1,2}^{2,1}, \widetilde{\phi}_{1,2}^{3,1}\right\}=\{\mathrm{OS}, \mathrm{E}, \mathrm{OS}\}=\{(1.0000, \quad 1.2222$, $1.8571,2.3333),(1.0000,1.0000,1.0000,1.0000)$, (1.0000, $1.2222,1.8571,2.3333)\}$. Based on formulas (11)-(13), the rough boundary interval of $\widetilde{\phi}_{1,2}^{1,1}=$ OS in $\tilde{\rho}_{1,2}^{1}=$ $\left\{\widetilde{\phi}_{1,2}^{1,1}, \widetilde{\phi}_{1,2}^{2,1}, \widetilde{\phi}_{1,2}^{3,1}\right\}$ is obtained as $\operatorname{RBI}\left(\widetilde{\phi}_{1,2}^{1,1}\right)=\left[\operatorname{LRL}\left(\widetilde{\phi}_{1,2}^{1,1}\right)\right.$,

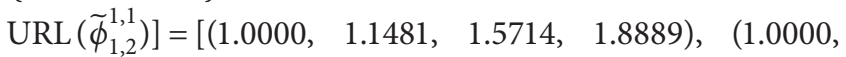
1.2222, $1.8571, \quad 2.3333)], \quad$ while $\quad \operatorname{RBI}\left(\tilde{\phi}_{1,2}^{2,1}\right)=$ $\left[\operatorname{LRL}\left(\widetilde{\phi}_{1,2}^{2,1}\right), \operatorname{URL}\left(\widetilde{\phi}_{1,2}^{2,1}\right)\right]=[(1.0000,1.0000,1.0000,1.0000)$, $(1.0000,1.1481,1.5714,1.8889)]$ and $\operatorname{RBI}\left(\tilde{\phi}_{1,2}^{3,1}\right)=$ $\left.\operatorname{LRL}\left(\widetilde{\phi}_{1,2}^{3,1}\right), \operatorname{URL}\left(\widetilde{\phi}_{1,2}^{3,1}\right)\right]=[(1.0000,1.1481,1.5714,1.8889)$, $(1.0000,1.2222,1.8571,2.3333)]$. According to the arithmetic operation rules shown in formulas (14)-(16), the rough boundary interval of $\tilde{\rho}_{1,2}^{1}=\left\{\widetilde{\phi}_{1,2}^{1,1}, \widetilde{\phi}_{1,2}^{2,1}, \widetilde{\phi}_{1,2}^{3,1}\right\}$ can be obtained as $\operatorname{RBI}\left(\widetilde{\rho}_{1,2}^{1}\right)=[(1.0000,1.0988,1.3809,1.5926)$, (1.0000, $1.1975,1.7619,2.1852)]$.
The rough boundary intervals of other elements in $\widetilde{\Theta}^{1}=$ $\left[\tilde{\rho}_{i, j}^{1}\right]_{10 \times 10}$ can be obtained by the same way. The RBI judgment matrix is constructed as $\widetilde{\Lambda}^{1}=\left[\widetilde{R B I}^{1}\left(\widetilde{\rho}_{i, j}^{1}\right)\right]_{10 \times 10}$. Then, $\widetilde{\Lambda}^{1}$ is decomposed into LRL matrix $\widetilde{\Lambda}_{\text {LRL }}^{1}$ and URL matrix $\widetilde{\Lambda}_{\text {URL }}^{1} \cdot \widetilde{\Lambda}_{\text {LRL }}^{1}$ is shown in Tables 3 and 4 , while $\widetilde{\Lambda}_{\text {URL }}^{1}$ is shown in Tables 5 and 6 .

According to formula (8), $\widetilde{\Lambda}_{\mathrm{LRL}}^{1}$ and $\tilde{\Lambda}_{\mathrm{URL}}^{1}$ are converted into real number forms $\Lambda_{\mathrm{LRL}}^{1}$, shown in Table 7 , and $\Lambda_{\mathrm{URL}}^{1}$ shown in Table 8.

The eigenvectors of $\Lambda_{\mathrm{LRL}}^{1}$ and $\Lambda_{\mathrm{URL}}^{1}$ corresponding to the maximum eigenvalue are obtained, respectively, as $\operatorname{Eig}\left(\Lambda_{\mathrm{LRL}}^{1}\right)$ and $\operatorname{Eig}\left(\Lambda_{\mathrm{URL}}^{1}\right)$. After averaging the two eigenvectors, an average vector is obtained as $\operatorname{Eig}\left(\Lambda_{\text {Aver }}^{1}\right)=[0.3353,0.3039,0.3235,0.3009,0.3108,0.3354$, $0.2915,0.3100,0.3234,0.3214]^{\mathrm{T}}$.

The index value of ten intelligent manufacturing project alternatives on index 1 is obtained as $\operatorname{Eig}\left(\Lambda_{\text {Aver }}^{1}\right)$. After solving the index values of ten intelligent manufacturing project alternatives on other indexes by the same way, the index value matrix of ten intelligent manufacturing project alternatives on all indexes is obtained as $X=\left[x_{i, t}\right]_{10 \times 9}$, as shown in Table 9.

Subjective weight solved by the complex networks method, ANP method, and Delphi method is shown in Table 10, while objective weight solved by the entropy method, CRITIC method, and standard deviation method is shown in Table 11.

As shown in Figure 10, the weight synthesis has three stages. Stage 1 and stage 2 have two substages, respectively.

The synthesized weight obtained in each stage is shown in Table 12.

According to formulas (40) and (41), the weighted preference degree matrix is obtained, as shown in Table 13.

According to formulas (42) and (43), the outflow, inflow, net flow, and final rank are obtained, as shown in Table 14.

\section{Discussion of the Results}

In order to make a final selection of the optimal alternatives, it is necessary to assess the reliability of the results obtained by the initial model. The most common means of assessing the reliability of the results is to compare them with other MCDM techniques. The discussion of the results is presented using the comparison of three MCDM methods (PROMETHEE II, TOPSIS, and VIKOR). These methods were chosen because they have so far given stable and reliable results [27-30]. TOPSIS and VIKOR methods were modified using fuzzy rough-sets AHP and multistage weight synthesis techniques proposed in this paper, which are called FRSA-MSWS-TOPSIS and FRSA-MSWS-VIKOR. These two modified models are compared with the proposed FRSA-MSWS-PII. Additionally, the models for comparison (FRSA-MSWS-TOPSIS and FRSA-MSWS-VIKOR) are divided into multiple submodels which are with synthesis of different quantity weights. In the second part of this section, a sensitivity analysis $[31,32]$ of the proposed FRSA-MSWSPII model was carried out through 27 scenarios. 
TABLE 3: LRL matrix $\tilde{\Lambda}_{\text {LRL }}^{1}$ (part 1: columns 1-5).

\begin{tabular}{|c|c|c|c|c|c|}
\hline Alter. & 1 & 2 & 3 & 4 & 5 \\
\hline 1 & $(1,1,1,1)$ & $\begin{array}{c}(1.0000,1.0988,1.3809 \\
1.5926)\end{array}$ & $\begin{array}{r}(1.1037,1.67 \\
1.93\end{array}$ & $\begin{array}{r}(0.6468,1.7128, \\
1.8657)\end{array}$ & $\begin{array}{r}(0.9951,1.302 \\
1.737\end{array}$ \\
\hline 2 & $\begin{array}{c}(0.5336,0.5676,1.0397 \\
1.3301)\end{array}$ & $(1,1,1,1)$ & $\begin{array}{c}(0.4684,0.9725,1.1776 \\
1.3317)\end{array}$ & $\begin{array}{r}(0.8246,1.0 \\
1.65\end{array}$ & $\begin{array}{l}39,0.9974 \text {, } \\
6)\end{array}$ \\
\hline 3 & $\begin{array}{r}(1.1489,1.45 \\
1.58\end{array}$ & $\begin{array}{c}(0.4953,0.5825,0.8568, \\
1.6916)\end{array}$ & $(1,1,1$ & $\begin{array}{c}(0.8178,1.1612,1.2975 \\
1.9428)\end{array}$ & $\begin{array}{r}(1.0195,1.0 \\
1.9\end{array}$ \\
\hline 4 & $\begin{array}{r}(0.7188,1 . \\
1.7\end{array}$ & $\begin{array}{r}(0.9026,1 . \\
1.4\end{array}$ & $\begin{array}{r}(0.7571,0.9 \\
1.2\end{array}$ & $(1,1,1,1)$ & $\begin{array}{r}(0.5961,1.1 \\
1.3\end{array}$ \\
\hline 5 & $\begin{array}{c}(0.5566,0.9454,1.2 \\
1.4644)\end{array}$ & $\begin{array}{c}(0.6137,0.9540,1.2736, \\
1.3970)\end{array}$ & $\begin{array}{r}(1.4355,1.45 \\
1.91\end{array}$ & $\begin{array}{c}(1.1477,1.1610,1.3913 \\
1.4760)\end{array}$ & $(1,1$, \\
\hline 6 & $\begin{array}{r}(0.8475,1 \\
1 .\end{array}$ & $\begin{aligned}(1.0563,1 \\
1 .\end{aligned}$ & $\begin{array}{r}(0.7848,1.0 \\
1.9\end{array}$ & 3) 1.7861 , & $\begin{array}{c}(0.4996,1.3061,1.4028, \\
1.4263)\end{array}$ \\
\hline 7 & $\begin{array}{r}(0.6408,0.67 \\
0.76\end{array}$ & $\begin{array}{r}(1.1400,1.22 \\
1.52\end{array}$ & $\begin{array}{r}(0.5379,0.72 \\
1.25\end{array}$ & $\begin{array}{c}(0.6112,1.1761,1.4969 \\
1.8638)\end{array}$ & $\begin{array}{r}(0.6579,0.7 \\
1.3\end{array}$ \\
\hline 8 & $\begin{array}{r}(0.5216,0.600 \\
1.726\end{array}$ & $\begin{array}{r}(1.0414,1.1 \\
1.68\end{array}$ & 5, 1.5495 & 49, 1.7300 , & 9) 3.6511 , \\
\hline 9 & $\begin{array}{c}(1.1202,1.2001,1.3715 \\
1.3804)\end{array}$ & $\begin{array}{c}(0.9248,1.1256,1.1425 \\
1.2045)\end{array}$ & $\begin{array}{c}(1.0368,1.2759,1.4487 \\
1.7079)\end{array}$ & $\begin{array}{c}(0.7720,0.9169,1.3599, \\
1.4148)\end{array}$ & $\begin{array}{c}(1.2160,1.5583,1.6575, \\
1.8508)\end{array}$ \\
\hline 10 & $\begin{array}{c}(0.4973,1.1939,1.2250 \\
1.6033)\end{array}$ & $\begin{array}{c}(0.7335,0.8219,1.3439, \\
1.6985)\end{array}$ & $\begin{array}{c}(1.2856,1.4828,1.4831 \\
1.5321)\end{array}$ & $\begin{array}{c}(0.5005,1.3199,1.4872, \\
1.8169)\end{array}$ & $\begin{array}{c}(0.6924,1.0332,1.4494, \\
1.7761)\end{array}$ \\
\hline
\end{tabular}

TABLE 4: LRL matrix $\widetilde{\Lambda}_{\text {LRL }}^{1}$ (part 2: columns 6-10).

\begin{tabular}{|c|c|c|c|c|c|}
\hline Alter. & 6 & 7 & 8 & 9 & 10 \\
\hline 1 & $\begin{array}{r}(0.8231,1.43 \\
1.93\end{array}$ & $\begin{array}{c}(0.7973,0.8449,1.4851, \\
1.7588)\end{array}$ & $\begin{array}{r}(0.4518,1.04 \\
1.86\end{array}$ & $\begin{array}{r}(1.0328,1.0 \\
1.28\end{array}$ & $\begin{array}{r}(1.0170,1.0771, \\
1.6334)\end{array}$ \\
\hline 2 & $\begin{array}{r}(0.5954,0.66 \\
1.52\end{array}$ & $\begin{array}{r}(0.6231,0.66 \\
1.501\end{array}$ & $\begin{array}{r}(1.3189,1.5 \\
1.85\end{array}$ & $\begin{array}{r}(0.4508,1.3 \\
1.9\end{array}$ & $\begin{array}{r}(0.6138,0.6 \\
1.4\end{array}$ \\
\hline 3 & $\begin{array}{c}(0.5483,1.5937,1.7837 \\
1.8983)\end{array}$ & $\begin{array}{r}(0.4979,0.65 \\
1.067\end{array}$ & $\begin{array}{r}(0.5462,0.9 \\
1.9\end{array}$ & $\begin{array}{r}(0.5753,0.5 \\
1.6\end{array}$ & $\begin{array}{r}(0.4660,0.9 \\
1.6\end{array}$ \\
\hline 4 & $\begin{array}{r}(0.7969,0 . \\
1.9\end{array}$ & $\begin{array}{r}(0.6649,1.2 \\
1.93\end{array}$ & 1.7121, & $\begin{array}{r}(0.6747,1 . \\
1.7\end{array}$ & $\begin{array}{r}(0.5677,0 . \\
1.0\end{array}$ \\
\hline 5 & $\begin{array}{c}(1.2083,1.2108,1.8492 \\
1.9144)\end{array}$ & $\begin{array}{r}(0.7146,0.80 \\
1.12\end{array}$ & 2, 1.8526 & $\begin{array}{r}(0.6320,0.7 \\
1.5\end{array}$ & 2, 1.1001, \\
\hline 6 & $(1,1,1,1)$ & $\begin{array}{c}(0.5999,1.2586,1.7172, \\
1.7181)\end{array}$ & $\begin{array}{r}(1.1534,1.45 \\
1.95\end{array}$ & $\begin{array}{r}(0.8006,1.04 \\
1.363\end{array}$ & $\begin{array}{r}(0.9830,1.5 \\
1.9 ?\end{array}$ \\
\hline 7 & $\begin{array}{c}(0.4849,0.8541,1.3713 \\
1.7175)\end{array}$ & $(1,1,1,1)$ & $\begin{array}{r}(0.5054,0.949 \\
1.666 ?\end{array}$ & $\begin{array}{c}(0.7472,0.9787,1.3915 \\
1.5946)\end{array}$ & $\begin{array}{c}(0.5912,0.7424,0.8956, \\
1.3431)\end{array}$ \\
\hline 8 & $\begin{array}{c}(1.0599,1.2561,1.4907 \\
1.5989)\end{array}$ & $\begin{array}{c}(0.5189,0.8263,1.1357 \\
1.6201)\end{array}$ & $(1,1,1,1)$ & $\begin{array}{c}(0.4803,1.1356,1.5093 \\
1.5413)\end{array}$ & $\begin{array}{c}(1.2220,1.3407,1.7600, \\
1.8463)\end{array}$ \\
\hline 9 & $\begin{array}{c}(0.5794,1.4202,1.4745 \\
1.5811)\end{array}$ & $\begin{array}{c}(0.4763,0.6373,1.3491, \\
1.8889)\end{array}$ & $\begin{array}{c}(0.4891,1.1740,1.4547 \\
1.7554)\end{array}$ & $(1,1,1,1)$ & $\begin{array}{c}(0.5341,0.7245,0.9628, \\
1.4774)\end{array}$ \\
\hline 10 & $\begin{array}{c}(0.8962,1.0925,1.5457, \\
1.9992)\end{array}$ & $\begin{array}{c}(0.8964,1.5462,1.5810 \\
1.6611)\end{array}$ & $\begin{array}{c}(0.9733,1.3922,1.5989 \\
1.6593)\end{array}$ & $\begin{array}{c}(0.5296,1.5882,1.6884 \\
1.8302)\end{array}$ & $(1,1,1,1)$ \\
\hline
\end{tabular}

5.1. Comparing the Ranks of Different Models. FRSA-MSWS-TOPSIS model and FRSA-MSWS-TOPSIS model are divided into multiple submodels. All models including the proposed model (model 1) are as follows:

(1) Model 1: proposed model (FRSA-MSWS-PII) with synthesis of six weights $\left(\mathrm{SW}^{1}, \mathrm{SW}^{2}, \mathrm{SW}^{3}+\mathrm{OW}^{1}\right.$, $\mathrm{OW}^{2}, \mathrm{OW}^{3}$ )

(2) Model 2: FRSA-MSWS-TOPSIS with synthesis of two weights

Model 2.1: $\mathrm{SW}^{1}+\mathrm{OW}^{1}$

Model 2.2: $\mathrm{SW}^{1}+\mathrm{OW}^{2}$
Model 2.3: $\mathrm{SW}^{2}+\mathrm{OW}^{2}$

Model 2.4: $\mathrm{SW}^{2}+\mathrm{OW}^{3}$

Model 2.5: $\mathrm{SW}^{3}+\mathrm{OW}^{1}$

Model 2.6: $\mathrm{SW}^{3}+\mathrm{OW}^{3}$

(3) Model 3: FRSA-MSWS-VIKOR with synthesis of two weights

Model 3.1: $\mathrm{SW}^{1}+\mathrm{OW}^{1}$

Model 3.2: $\mathrm{SW}^{1}+\mathrm{OW}^{2}$

Model 3.3: $\mathrm{SW}^{2}+\mathrm{OW}^{2}$

Model 3.4: $\mathrm{SW}^{2}+\mathrm{OW}^{3}$

Model 3.5: $\mathrm{SW}^{3}+\mathrm{OW}^{1}$

Model 3.6: $\mathrm{SW}^{3}+\mathrm{OW}^{3}$ 
TABLe 5: URL matrix $\widetilde{\Lambda}_{\text {URL }}^{1}$ (part 1: columns 1-5).

\begin{tabular}{|c|c|c|c|c|c|}
\hline Alter. & 1 & 2 & 3 & 4 & 5 \\
\hline 1 & $(1,1,1,1)$ & $\begin{array}{r}(1.0000,1.197 \\
2.1852\end{array}$ & $\begin{array}{c}(1.3959,1.8678,2.56 \\
2.9058)\end{array}$ & $\begin{array}{c}(0.8786,2.2426,2 \\
4.7228)\end{array}$ & $\begin{array}{c}(1.4288,2.4658,2 \\
3.9657)\end{array}$ \\
\hline 2 & $\begin{array}{c}(1.3456,1.9678,2.5142, \\
2.8548)\end{array}$ & $(1,1,1,1)$ & $\begin{array}{c}(1.1568,1.4847,2.5474 \\
3.0198)\end{array}$ & $\begin{array}{c}(1.0122,1.0903,2.8725, \\
4.8158)\end{array}$ & $\begin{array}{c}(0.8339,0.8947,1.5098, \\
2.6066)\end{array}$ \\
\hline 3 & $\begin{array}{r}(1.4519,1.59 \\
2.438\end{array}$ & $\begin{array}{c}(1.8749,2.4067,2.8435 \\
3.2298)\end{array}$ & $(1,1,1$, & $\begin{array}{r}(1.3095,1.87 \\
3.42\end{array}$ & $\begin{array}{r}(0.8830,2.7 \\
4.1\end{array}$ \\
\hline 4 & $\begin{array}{r}(0.9330,1 . \\
2.5\end{array}$ & $\begin{array}{r}(0.8341,1.16 \\
2.96\end{array}$ & $\begin{array}{r}(0.9159,2.8 \\
3.8\end{array}$ & $(1,1,1,1)$ & $\begin{array}{r}(0.9411,2.2 \\
2.3\end{array}$ \\
\hline 5 & $\begin{array}{r}(1.6968,2.38 \\
4.868\end{array}$ & $\begin{array}{r}(0.9998,1.7 \\
2.51\end{array}$ & $\begin{array}{r}(1.2597,1.3 \\
2.36\end{array}$ & $\begin{array}{c}(1.5705,2.2564,2.4946, \\
2.5479)\end{array}$ & $(1,1,1$ \\
\hline 6 & $\begin{array}{r}(1.9121,1.98 \\
2.71\end{array}$ & $\begin{array}{r}(1.6729,2.4 \\
3.9\end{array}$ & 0, 2.2768 & 7, 2.0937, & $\begin{array}{r}(0.9090,1.5 \\
1.8\end{array}$ \\
\hline 7 & $\begin{array}{c}(0.8938,1.4201,2.1974 \\
3.0621)\end{array}$ & $\begin{array}{c}(1.0727,1.8788,2.6766 \\
4.4705)\end{array}$ & $\begin{array}{c}(1.1865,1.2597,1.5389 \\
4.6016)\end{array}$ & $\begin{array}{r}(1.5736,2.03 \\
2.44\end{array}$ & $\begin{array}{r}(0.9572,1.02 \\
2.76\end{array}$ \\
\hline 8 & $\begin{array}{c}(0.9447,1.4976,2.3286, \\
2.8905)\end{array}$ & $\begin{array}{c}(1.2111,1.7803,1.8775 \\
3.5145)\end{array}$ & $\begin{array}{c}(1.0618,1.1577,2.2412 \\
2.8931)\end{array}$ & $\begin{array}{r}(0.9720,1.98 \\
2.99\end{array}$ & $\begin{array}{c}(0.9858,2.4791,2.5981, \\
2.7111)\end{array}$ \\
\hline 9 & $\begin{array}{c}(0.8528,1.1187,1.6901, \\
1.8615)\end{array}$ & $\begin{array}{c}(1.9187,1.9237,2.5988, \\
4.1383)\end{array}$ & $\begin{array}{c}(1.5716,2.7271,2.8658 \\
3.1107)\end{array}$ & $\begin{array}{c}(1.3071,1.6180,1.8360 \\
2.6575)\end{array}$ & $\begin{array}{c}(1.5352,1.6308,2.3372, \\
2.7600)\end{array}$ \\
\hline 10 & $\begin{array}{c}(2.1417,2.1589,2.7904 \\
4.4097)\end{array}$ & $\begin{array}{c}(0.8631,1.5053,1.8778 \\
2.7503)\end{array}$ & $\begin{array}{c}(1.0816,1.1919,1.5187 \\
2.9980)\end{array}$ & $\begin{array}{c}(1.2190,1.6116,1.8136 \\
4.9229)\end{array}$ & $\begin{array}{c}(1.2200,1.3066,1.7422, \\
1.8604)\end{array}$ \\
\hline
\end{tabular}

TABLE 6: URL matrix $\widetilde{\Lambda}_{\text {URL }}^{1}$ (part 2: columns 6-10).

\begin{tabular}{|c|c|c|c|c|c|}
\hline Alter. & 6 & 7 & 8 & 9 & 10 \\
\hline 1 & $\begin{array}{c}(1.0856,1.4359,2.2780 \\
2.3293)\end{array}$ & $\begin{array}{c}(0.8282,1.5578,2.2857, \\
2.5171)\end{array}$ & $\begin{array}{c}(1.7336,1.8140,1.8174 \\
4.0347)\end{array}$ & $\begin{array}{c}(1.2599,1.2930,1.5676 \\
2.9902)\end{array}$ & $\begin{array}{c}(2.1814,2.4984,2.8523, \\
4.8855)\end{array}$ \\
\hline 2 & $\begin{array}{c}(1.9559,1.9668,2.6945 \\
2.8364)\end{array}$ & $\begin{array}{c}(1.0309,1.1247,1.2174 \\
1.8890)\end{array}$ & $\begin{array}{c}(2.0821,2.5939,2.7338 \\
4.9534)\end{array}$ & $\begin{array}{c}(1.7569,1.8550,1.9609 \\
2.5630)\end{array}$ & $\begin{array}{c}(0.9146,2.0622,2.8486 \\
3.8604)\end{array}$ \\
\hline 3 & $\begin{array}{c}(2.5282,2.6897,2.9562, \\
2.9657)\end{array}$ & $\begin{array}{c}(1.4502,1.4629,2.1983, \\
2.8661)\end{array}$ & $\begin{array}{c}(0.9020,1.4561,1.9119 \\
3.9980)\end{array}$ & $\begin{array}{c}(1.0401,1.9743,2.7913 \\
4.2684)\end{array}$ & $\begin{array}{c}(0.9066,2.1276,2.2694 \\
3.0096)\end{array}$ \\
\hline 4 & $\begin{array}{c}(1.3612,1.9131,2.4528 \\
3.7361)\end{array}$ & $\begin{array}{c}(1.1284,1.3665,1.8680, \\
2.6496)\end{array}$ & $\begin{array}{c}(1.2325,1.3524,2.1553 \\
2.7878)\end{array}$ & $\begin{array}{c}(1.5721,2.1685,2.6767 \\
2.9556)\end{array}$ & $\begin{array}{c}(1.0085,1.2046,1.3279, \\
1.7180)\end{array}$ \\
\hline 5 & $\begin{array}{c}(1.2671,1.5430,1.6123 \\
2.7801)\end{array}$ & $\begin{array}{c}(1.4844,1.5762,1.7465, \\
2.8314)\end{array}$ & $\begin{array}{c}(1.3677,1.6992,1.9013, \\
2.1088)\end{array}$ & $\begin{array}{c}(1.4527,1.5013,1.7332 \\
2.9330)\end{array}$ & $\begin{array}{c}(1.1802,1.2257,1.5547, \\
1.9670)\end{array}$ \\
\hline 6 & $(1,1,1,1)$ & $\begin{array}{c}(1.1297,2.2511,2.3894 \\
2.9781)\end{array}$ & $\begin{array}{c}(0.9836,1.3593,1.7513, \\
2.6157)\end{array}$ & $\begin{array}{c}(1.3540,1.4390,1.9142 \\
2.1576)\end{array}$ & $\begin{array}{c}(1.0371,2.0850,2.7939, \\
4.4945)\end{array}$ \\
\hline 7 & $\begin{array}{c}(1.1553,1.4880,1.5508 \\
1.7356)\end{array}$ & $(1,1,1,1)$ & $\begin{array}{c}(1.1869,1.4414,1.8417 \\
2.3879)\end{array}$ & $\begin{array}{c}(1.3343,1.3919,2.8183 \\
4.0151)\end{array}$ & $\begin{array}{c}(1.7366,2.0025,2.3034, \\
3.5067)\end{array}$ \\
\hline 8 & $\begin{array}{c}(1.1300,1.5650,1.9010 \\
2.0894)\end{array}$ & $\begin{array}{c}(1.5903,2.3132,2.4199, \\
2.4578)\end{array}$ & $(1,1,1,1)$ & $\begin{array}{c}(1.3946,1.5279,1.6276 \\
1.7335)\end{array}$ & $\begin{array}{c}(1.3428,2.0892,2.4250, \\
3.5989)\end{array}$ \\
\hline 9 & $\begin{array}{c}(2.4919,2.7597,2.9611, \\
3.2421)\end{array}$ & $\begin{array}{c}(1.6795,1.8655,2.6587, \\
2.6980)\end{array}$ & $\begin{array}{c}(1.5653,2.0299,2.6733, \\
2.6790)\end{array}$ & $(1,1,1,1)$ & $\begin{array}{c}(1.0599,2.7767,2.9745, \\
3.0679)\end{array}$ \\
\hline 10 & $\begin{array}{c}(1.2209,1.8226,2.4807 \\
2.6000)\end{array}$ & $\begin{array}{c}(1.0587,1.6723,2.0247, \\
2.3236)\end{array}$ & $\begin{array}{c}(1.0306,1.0814,2.0090 \\
2.8380)\end{array}$ & $\begin{array}{c}(0.9603,0.9948,2.5564, \\
4.7606)\end{array}$ & $(1,1,1,1)$ \\
\hline
\end{tabular}

TABLE 7: Real number form matrix $\Lambda_{\mathrm{LRL}}^{1}$.

\begin{tabular}{lcccccccccc}
\hline Alter. & 1 & 2 & 3 & 4 & 5 & 6 & 7 & 8 & 9 \\
\hline 1 & 1 & 1.5314 & 1.6206 & 1.4502 & 1.3533 & 1.4101 & 1.2253 & 1.1829 & 1.1195 & 1.2467 \\
2 & 0.8732 & 1 & 0.9696 & 1.1815 & 0.9277 & 0.9341 & 1.0056 & 1.6240 & 1.3692 & 0.9003 \\
3 & 1.3962 & 0.9456 & 1 & 1.3245 & 1.4052 & 1.3976 & 0.7491 & 1.1550 & 1.0641 & 1.0024 \\
4 & 1.2965 & 1.2240 & 0.9899 & 1 & 1.0433 & 1.2840 & 1.4147 & 1.3558 & 1.2670 & 0.7829 \\
5 & 1.0521 & 1.0520 & 1.6035 & 1.2950 & 1 & 1.5459 & 0.8802 & 1.3835 & 1.0907 & 1.3823 \\
6 & 1.4157 & 1.4310 & 1.3540 & 1.4816 & 1.1058 & 1 & 1.3005 & 1.5629 & 1.1353 & 1.5446 \\
7 & 0.7071 & 1.3030 & 0.8849 & 1.2772 & 0.9513 & 1.1062 & 1 & 1.0778 & 1.1772 & 0.9094 \\
8 & 0.9719 & 1.3723 & 1.3468 & 1.2719 & 1.1681 & 1.3485 & 1.0335 & 1 & 1.1417 & 1.5417 \\
9 & 1.2668 & 1.0891 & 1.3683 & 1.1145 & 1.5616 & 1.2089 & 1.0983 & 1.1979 & 1 & 0.9408 \\
10 & 1.1048 & 1.1561 & 1.4336 & 1.2495 & 1.2373 & 1.3923 & 1.3778 & 1.3899 & 1.3436 & 1 \\
\hline
\end{tabular}


TABLe 8: Real number form matrix $\Lambda_{\mathrm{URL}}^{1}$.

\begin{tabular}{lcccccccccc}
\hline Alter. & 1 & 2 & 3 & 4 & 5 & 6 & 7 & 8 & 9 \\
\hline 1 & 1 & 1.9481 & 2.1786 & 2.6741 & 2.6765 & 1.7774 & 1.7807 & 2.5275 & 1.8617 & 3.2143 \\
2 & 2.1596 & 1 & 2.0555 & 2.5039 & 1.5031 & 2.3644 & 1.3543 & 3.2199 & 2.0662 & 2.4149 \\
3 & 1.8819 & 2.5825 & 1 & 2.2090 & 2.6034 & 2.7819 & 2.0116 & 2.1619 & 2.5455 & 2.0433 \\
4 & 1.7712 & 1.6605 & 2.5614 & 1 & 1.8669 & 2.4042 & 1.7760 & 1.8956 & 2.3310 & 1.3261 \\
5 & 3.0017 & 1.7821 & 1.6409 & 2.1853 & 1 & 1.8684 & 1.9738 & 1.7633 & 1.9750 & 1.4944 \\
6 & 2.2110 & 2.7231 & 2.5680 & 2.0662 & 1.4638 & 1 & 2.1489 & 1.7024 & 1.7196 & 2.6385 \\
7 & 1.9067 & 2.5757 & 2.3581 & 2.1032 & 1.6022 & 1.4725 & 1 & 1.7266 & 2.4189 & 2.4427 \\
8 & 1.9157 & 2.1776 & 1.8503 & 2.1235 & 2.0933 & 1.6615 & 2.1507 & 1 & 1.5697 & 2.3904 \\
9 & 1.3786 & 2.7131 & 2.5055 & 1.8854 & 2.0731 & 2.8643 & 2.2239 & 2.2266 & 1 & 2.3587 \\
10 & 2.9505 & 1.7620 & 1.7784 & 2.5948 & 1.5328 & 2.0168 & 1.7550 & 1.7606 & 2.3935 & 1 \\
\hline
\end{tabular}

TABLe 9: Index value matrix $X=\left[x_{i, t}\right]_{10 \times 9}$.

\begin{tabular}{lccccccccc}
\hline & Index 1 & Index 2 & Index 3 & Index 4 & Index 5 & Index 6 & Index 7 & Index 8 & Index 9 \\
\hline Alter. 1 & 0.3353 & 0.8333 & 0.9152 & 0.2143 & 0.9220 & 0.6691 & 0.1878 & 0.3506 & 0.5922 \\
Alter. 2 & 0.3039 & 0.9618 & 0.9684 & 0.2419 & 0.9735 & 0.9615 & 0.5368 & 0.8203 & 0.2277 \\
Alter. 3 & 0.3235 & 0.4796 & 0.9242 & 0.8130 & 0.9635 & 0.6902 & 0.1321 & 0.8642 & 0.9406 \\
Alter. 4 & 0.3009 & 0.7109 & 0.7820 & 0.7688 & 0.4530 & 0.6899 & 0.2541 & 0.7354 & 0.1286 \\
Alter. 5 & 0.3108 & 0.3492 & 0.1416 & 0.1874 & 0.8411 & 0.7253 & 0.3854 & 0.9552 & 0.1310 \\
Alter. 6 & 0.3354 & 0.4949 & 0.4434 & 0.7890 & 0.8157 & 0.2682 & 0.5408 & 0.5010 & 0.6817 \\
Alter. 7 & 0.2915 & 0.7384 & 0.7792 & 0.3484 & 0.7117 & 0.6896 & 0.2464 & 0.2071 & 0.5485 \\
Alter. 8 & 0.3100 & 0.9638 & 0.4063 & 0.6267 & 0.3014 & 0.7761 & 0.3296 & 0.5554 & 0.7292 \\
Alter. 9 & 0.3234 & 0.9018 & 0.9634 & 0.5925 & 0.2248 & 0.2344 & 0.3318 & 0.8566 & 0.3289 \\
Alter. 10 & 0.3214 & 0.8329 & 0.3192 & 0.9363 & 0.4150 & 0.2769 & 0.3260 & 0.3260 & 0.5260 \\
\hline
\end{tabular}

TABle 10: Subjective weight.

\begin{tabular}{|c|c|c|c|c|c|c|c|c|c|}
\hline & Index 1 & Index 2 & Index 3 & Index 4 & Index 5 & Index 6 & Index 7 & Index 8 & Index 9 \\
\hline Complex networks method (SW $\left.{ }^{1}\right)$ & 0.0685 & 0.0309 & 0.1646 & 0.0656 & 0.0258 & 0.1591 & 0.1396 & 0.2425 & 0.1034 \\
\hline ANP method $\left(\mathrm{SW}^{2}\right)$ & 0.0284 & 0.0913 & 0.0711 & 0.1715 & 0.1104 & 0.1162 & 0.1852 & 0.1049 & 0.1209 \\
\hline Delphi method $\left(\mathrm{SW}^{3}\right)$ & 0.0830 & 0.0497 & 0.0607 & 0.0970 & 0.1141 & 0.1530 & 0.1323 & 0.0875 & 0.2226 \\
\hline
\end{tabular}

TABLE 11: Objective weight.

\begin{tabular}{|c|c|c|c|c|c|c|c|c|c|}
\hline & Index 1 & Index 2 & Index 3 & Index 4 & Index 5 & Index 6 & Index 7 & Index 8 & Index 9 \\
\hline Entropy method $\left(\mathrm{SW}^{1}\right)$ & 0.1154 & 0.1133 & 0.1099 & 0.1091 & 0.1108 & 0.1111 & 0.1117 & 0.1110 & 0.1077 \\
\hline CRITIC method $\left(\mathrm{SW}^{2}\right)$ & 0.1077 & 0.1153 & 0.1024 & 0.1189 & 0.1066 & 0.1143 & 0.1163 & 0.1116 & 0.1069 \\
\hline Standard deviation method $\left(\mathrm{SW}^{3}\right)$ & 0.0072 & 0.1070 & 0.1515 & 0.1388 & 0.1416 & 0.1226 & 0.0663 & 0.1306 & 0.1344 \\
\hline
\end{tabular}

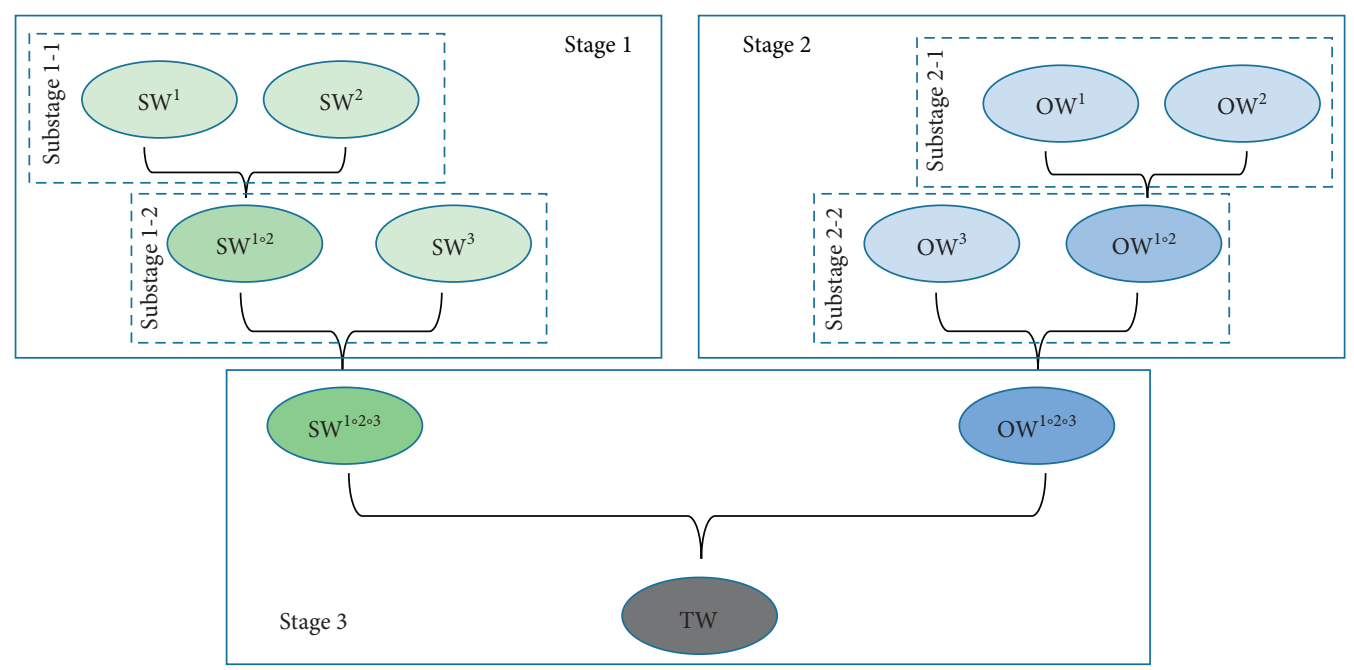

FIGURE 10: The weight synthesis process. 
TABLE 12: The synthesized weight obtained in each stage.

\begin{tabular}{lcccccccccc}
\hline & Synthesis coefficients & Index 1 & Index 2 & Index 3 & Index 4 & Index 5 & Index 6 & Index 7 & Index 8 & Index 9 \\
\hline Substage 1-1: $\mathrm{SW}^{1 \circ 2}$ & 0.3131 and 0.6869 & 0.0409 & 0.0724 & 0.1004 & 0.1384 & 0.0839 & 0.1296 & 0.1709 & 0.1480 & 0.1154 \\
Substage 1-2: $\mathrm{SW}^{1 \circ 2 \circ 3}$ & 0.6181 and 0.3819 & 0.0570 & 0.0638 & 0.0852 & 0.1226 & 0.0954 & 0.1385 & 0.1562 & 0.1249 & 0.1564 \\
Substage 2-1: $\mathrm{OW}^{102}$ & 0.7110 and 0.2890 & 0.1132 & 0.1139 & 0.1077 & 0.1119 & 0.1096 & 0.1120 & 0.1130 & 0.1111 & 0.1075 \\
Substage 2-2: $\mathrm{OW}^{1 \circ 2 \circ 3}$ & 0.4289 and 0.5711 & 0.0527 & 0.1100 & 0.1327 & 0.1273 & 0.1279 & 0.1181 & 0.0864 & 0.1222 & 0.1228 \\
Stage 3: TW & 0.3509 and 0.6491 & 0.0542 & 0.0937 & 0.1161 & 0.1256 & 0.1165 & 0.1252 & 0.1108 & 0.1232 & 0.1346 \\
\hline
\end{tabular}

TABle 13: The weighted preference degree matrix.

\begin{tabular}{lcccccccccc}
\hline & Alter. 1 & Alter. 2 & Alter. 3 & Alter. 4 & Alter. 5 & Alter. 6 & Alter. 7 & Alter. 8 & Alter. 9 & Alter. 10 \\
\hline Alter. 1 & 0 & 0.1097 & 0.0784 & 0.2744 & 0.3406 & 0.3040 & 0.1158 & 0.2275 & 0.3077 & 0.3417 \\
Alter. 2 & 0.3107 & 0 & 0.2633 & 0.3761 & 0.3417 & 0.4448 & 0.4223 & 0.3916 & 0.2909 & 0.5367 \\
Alter. 3 & 0.3512 & 0.2610 & 0 & 0.2990 & 0.4132 & 0.4260 & 0.4460 & 0.4158 & 0.4229 & 0.5779 \\
Alter. 4 & 0.2334 & 0.1217 & 0.0645 & 0 & 0.3146 & 0.3027 & 0.2314 & 0.1943 & 0.2120 & 0.3286 \\
Alter. 5 & 0.1696 & 0.0251 & 0.0751 & 0.1781 & 0 & 0.2308 & 0.1711 & 0.2242 & 0.2525 & 0.3466 \\
Alter. 6 & 0.2542 & 0.2477 & 0.0974 & 0.2982 & 0.3858 & 0 & 0.3120 & 0.1972 & 0.3178 & 0.2443 \\
Alter. 7 & 0.0306 & 0.1140 & 0.0698 & 0.1867 & 0.3491 & 0.2484 & 0 & 0.1980 & 0.2872 & 0.2967 \\
Alter. 8 & 0.2483 & 0.2347 & 0.1425 & 0.2035 & 0.4120 & 0.2161 & 0.2838 & 0 & 0.2529 & 0.2619 \\
Alter. 9 & 0.2567 & 0.1170 & 0.1293 & 0.1556 & 0.3694 & 0.2919 & 0.2656 & 0.1974 & 0 & 0.2404 \\
Alter. 10 & 0.1489 & 0.2158 & 0.1373 & 0.1762 & 0.3675 & 0.1012 & 0.1628 & 0.1051 & 0.1939 & 0 \\
\hline
\end{tabular}

TABLE 14: The outflow, inflow, net flow, and final rank.

\begin{tabular}{lcccc}
\hline & Outflow & Inflow & Net flow & Final rank \\
\hline Alter. 1 & 2.0998 & 2.0036 & 0.0962 & 4 \\
Alter. 2 & 3.3781 & 1.4468 & 1.9313 & 2.5552 \\
Alter. 3 & 3.6129 & 1.0577 & -0.1445 & 1 \\
Alter. 4 & 2.0032 & 2.1477 & -1.6208 & 5 \\
Alter. 5 & 1.6731 & 3.2940 & -0.2111 & 10 \\
Alter. 6 & 2.3546 & 2.5657 & -0.6302 & 6 \\
Alter. 7 & 1.7805 & 2.4108 & 0.1045 & 3 \\
Alter. 8 & 2.2557 & 2.1512 & -0.5145 & 7 \\
Alter. 9 & 2.0233 & 2.5379 & -1.5660 & 9 \\
Alter. 10 & 1.6088 & 3.1748 & & 8 \\
\hline
\end{tabular}

(4) Model 4: FRSA-MSWS-TOPSIS with synthesis of three weights

Model 4.1: $\mathrm{SW}^{1}, \mathrm{SW}^{2}+\mathrm{OW}^{1}$

Model 4.2: $\mathrm{SW}^{2}, \mathrm{SW}^{3}+\mathrm{OW}^{2}$

Model 4.3: $\mathrm{SW}^{1}, \mathrm{SW}^{3}+\mathrm{OW}^{3}$

Model 4.4: $\mathrm{SW}^{1}+\mathrm{OW}^{1}, \mathrm{OW}^{2}$

Model 4.5: $\mathrm{SW}_{2}+\mathrm{OW}^{2}, \mathrm{OW}^{3}$

Model 4.6: $\mathrm{SW}^{3}+\mathrm{OW}^{1}, \mathrm{OW}^{3}$

(5) Model 5: FRSA-MSWS-VIKOR with synthesis of three weights

Model 5.1: $\mathrm{SW}^{1}, \mathrm{SW}^{2}+\mathrm{OW}^{1}$

Model 5.2: $\mathrm{SW}^{2}, \mathrm{SW}^{3}+\mathrm{OW}^{2}$

Model 5.3: $\mathrm{SW}^{1}, \mathrm{SW}^{3}+\mathrm{OW}^{3}$

Model 5.4: $\mathrm{SW}^{1}+\mathrm{OW}^{1}, \mathrm{OW}^{2}$

Model 5.5: $\mathrm{SW}^{2}+\mathrm{OW}^{2}, \mathrm{OW}^{3}$

Model 5.6: $\mathrm{SW}^{3}+\mathrm{OW}^{1}, \mathrm{OW}^{3}$

(6) Model 6: FRSA-MSWS-TOPSIS with synthesis of four weights

Model 6.1: $\mathrm{SW}^{1}, \mathrm{SW}^{2}+\mathrm{OW}^{1}, \mathrm{OW}^{2}$

Model 6.2: $\mathrm{SW}^{1}, \mathrm{SW}^{2}+\mathrm{OW}^{2}, \mathrm{OW}^{3}$
Model 6.3: $\mathrm{SW}^{2}, \mathrm{SW}^{3}+\mathrm{OW}^{1}, \mathrm{OW}^{3}$

Model 6.4: $\mathrm{SW}^{2}, \mathrm{SW}^{3}+\mathrm{OW}^{1}, \mathrm{OW}^{2}$

Model 6.5: $\mathrm{SW}^{1}, \mathrm{SW}^{3}+\mathrm{OW}^{2}, \mathrm{OW}^{3}$

Model 6.6: $\mathrm{SW}^{1}, \mathrm{SW}^{3}+\mathrm{OW}^{1}, \mathrm{OW}^{3}$

(7) Model 7: FRSA-MSWS-VIKOR with synthesis of four weights

Model 7.1: $\mathrm{SW}^{1}, \mathrm{SW}^{2}+\mathrm{OW}^{1}, \mathrm{OW}^{2}$

Model 7.2: $\mathrm{SW}^{1}, \mathrm{SW}^{2}+\mathrm{OW}^{2}, \mathrm{OW}^{3}$

Model 7.3: $\mathrm{SW}^{2}, \mathrm{SW}^{3}+\mathrm{OW}^{1}, \mathrm{OW}^{3}$

Model 7.4: $\mathrm{SW}^{2}, \mathrm{SW}^{3}+\mathrm{OW}^{1}, \mathrm{OW}^{2}$

Model 7.5: $\mathrm{SW}^{1}, \mathrm{SW}^{3}+\mathrm{OW}^{2}, \mathrm{OW}^{3}$

Model 7.6: $\mathrm{SW}^{1}, \mathrm{SW}^{3}+\mathrm{OW}^{1}, \mathrm{OW}^{3}$

(8) Model 8: FRSA-MSWS-TOPSIS with synthesis of five weights

Model 8.1: $\mathrm{SW}^{1}, \mathrm{SW}^{2}, \mathrm{SW}^{3}+\mathrm{OW}^{1}, \mathrm{OW}^{2}$ Model 8.2: $\mathrm{SW}^{1}, \mathrm{SW}^{2}, \mathrm{SW}^{3}+\mathrm{OW}^{2}, \mathrm{OW}^{3}$ Model 8.3: $\mathrm{SW}^{1}, \mathrm{SW}^{2}, \mathrm{SW}^{3}+\mathrm{OW}^{1}, \mathrm{OW}^{3}$ Model 8.4: $\mathrm{SW}^{1}, \mathrm{SW}^{2}+\mathrm{OW}^{1}, \mathrm{OW}^{2}, \mathrm{OW}^{3}$ Model 8.5: $\mathrm{SW}^{2}, \mathrm{SW}^{3}+\mathrm{OW}^{1}, \mathrm{OW}^{2}, \mathrm{OW}^{3}$ Model 8.6: $\mathrm{SW}^{1}, \mathrm{SW}^{3}+\mathrm{OW}^{1}, \mathrm{OW}^{2}, \mathrm{OW}^{3}$ 
TABLE 15: Comparison of the ranks of alternatives according to models 1, 2, and 3.

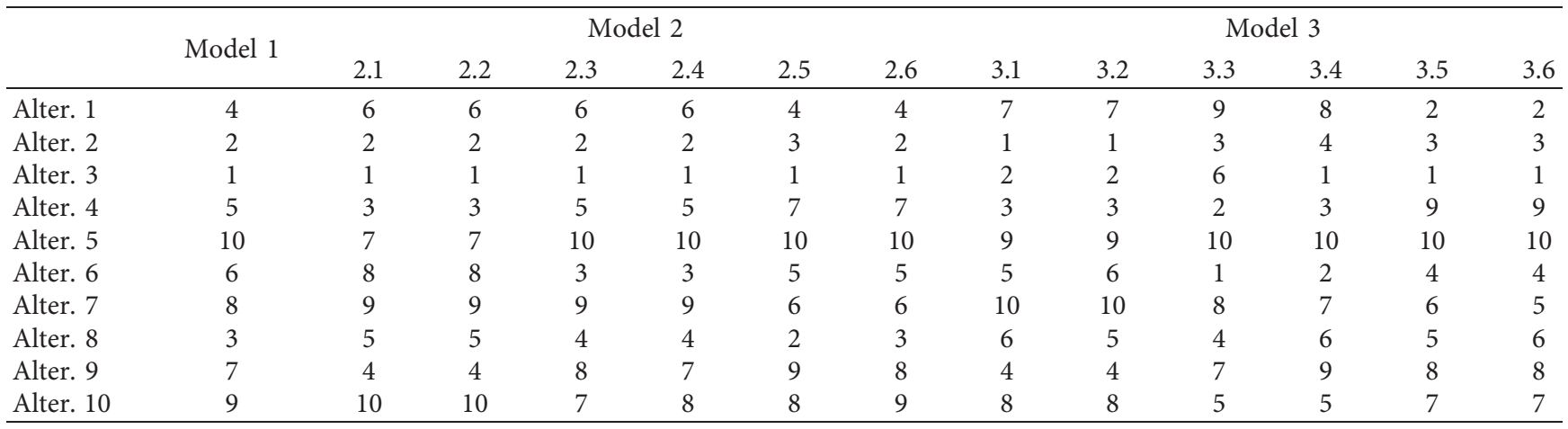

TABLE 16: Comparison of the ranks of alternatives according to models 1, 4, and 5 .

\begin{tabular}{lccccccccccccc}
\hline & Model 1 & \multicolumn{1}{c}{ Model 4} & \multicolumn{4}{c}{ Model 5} \\
& & 2.1 & 2.2 & 2.3 & 2.4 & 2.5 & 2.6 & 3.1 & 3.2 & 3.3 & 3.4 & 3.5 & 3.6 \\
\hline Alter. 1 & 4 & 7 & 5 & 4 & 6 & 6 & 3 & 7 & 4 & 4 & 7 & 7 & 3 \\
Alter. 2 & 2 & 2 & 3 & 2 & 2 & 2 & 2 & 1 & 1 & 2 & 1 & 2 & 2 \\
Alter. 3 & 1 & 1 & 1 & 1 & 1 & 1 & 1 & 3 & 6 & 1 & 2 & 1 & 1 \\
Alter. 4 & 5 & 3 & 7 & 5 & 3 & 5 & 7 & 2 & 9 & 6 & 3 & 4 & 8 \\
Alter. 5 & 10 & 8 & 10 & 9 & 8 & 10 & 10 & 9 & 10 & 10 & 9 & 10 & 10 \\
Alter. 6 & 6 & 6 & 4 & 7 & 7 & 3 & 5 & 5 & 2 & 5 & 5 & 3 & 4 \\
Alter. 7 & 8 & 9 & 6 & 8 & 9 & 8 & 6 & 10 & 5 & 9 & 10 & 8 & 6 \\
Alter. 8 & 3 & 4 & 2 & 3 & 5 & 4 & 4 & 4 & 3 & 3 & 4 & 6 \\
Alter. 9 & 7 & 5 & 9 & 6 & 4 & 7 & 8 & 6 & 8 & 7 & 6 & 9 \\
Alter. 10 & 9 & 10 & 8 & 10 & 10 & 9 & 9 & 8 & 7 & 8 & 8 & 5 \\
\hline
\end{tabular}

(9) Model 9: FRSA-MSWS-VIKOR with synthesis of five weights

$$
\begin{aligned}
& \text { Model 9.1: } \mathrm{SW}^{1}, \mathrm{SW}^{2}, \mathrm{SW}^{3}+\mathrm{OW}^{1}, \mathrm{OW}^{2} \\
& \text { Model 9.2: } \mathrm{SW}^{1}, \mathrm{SW}^{2}, \mathrm{SW}^{3}+\mathrm{OW}^{2}, \mathrm{OW}^{3} \\
& \text { Model 9.3: } \mathrm{SW}^{1}, \mathrm{SW}^{2}, \mathrm{SW}^{3}+\mathrm{OW}^{1}, \mathrm{OW}^{3} \\
& \text { Model 9.4: } \mathrm{SW}^{1}, \mathrm{SW}^{2}+\mathrm{OW}^{1}, \mathrm{OW}^{2}, \mathrm{OW}^{3} \\
& \text { Model 9.5: } \mathrm{SW}^{2}, \mathrm{SW}^{3}+\mathrm{OW}^{1}, \mathrm{OW}^{2}, \mathrm{OW}^{3} \\
& \text { Model 9.6: } \mathrm{SW}^{1}, \mathrm{SW}^{3}+\mathrm{OW}^{1}, \mathrm{OW}^{2}, \mathrm{OW}^{3}
\end{aligned}
$$

(10) Model 10: FRSA-MSWS-TOPSIS with synthesis of six weights $\left(\mathrm{SW}^{1}, \mathrm{SW}^{2}, \mathrm{SW}^{3}+\mathrm{OW}^{1}, \mathrm{OW}^{2}, \mathrm{OW}^{3}\right)$

(11) Model 11: FRSA-MSWS-VIKOR with synthesis of six weights $\left(\mathrm{SW}^{1}, \mathrm{SW}^{2}, \mathrm{SW}^{3}+\mathrm{OW}^{1}, \mathrm{OW}^{2}, \mathrm{OW}^{3}\right)$

Ranking of the alternatives according to the models used in order to assess the reliability of the results shows that alternative 3 remained in the first place for the majority of the models (Tables 15-19). There was a change in the ranking of alternative 3 using the FRSA-MSWS-TOPSIS model and FRSA-MSWS-TOPSIS model, whereby alternatives 3 and 2 changed places for the majority of the models.

In order to establish the connection between the results obtained using 51 different models (Tables 15-19), Spearman's correlation coefficient (SCC) was used. SCC of ranks is a useful and important indicator for determining the link between the results obtained by different models [31-33]. Additionally, the case in this study has ordinal variables or ranked variables, while SCC is suitable for use in this situation. In this paper, SCC was used to define the statistical significance of the difference between the ranks obtained by different models. The results of the comparison of ranks using SCC are shown in Tables 20-24.

The SCC values from Tables 20-24, which are with the average values of $0.64,0.74,0.77,0.90$, and 0.92 (all greater than 0.60 ), show a high correlation between the ranks among the models examined. In addition, the average value of SCC tends to increase when the number of synthesized weights increases, which reveals that the model tends to be stable when more weights are synthesized. Based on recommendations by Ghorabaee et al. [33], when all SCC values are greater than 0.8 , an extremely high correlation is shown. In our case, when the number of synthesized weights is 6 , all of the SCC values are significantly greater than 0.8 (Table 24) and the average value is 0.92 ; when the number of synthesized weights is 5 , most of the SCC values are significantly greater than 0.8 (Table 23) and the average value is 0.90 ; when the number of synthesized weights is 4 , most of the SCC values are also significantly greater than 0.8 (Table 22) and the average value is 0.77 (slightly less than 0.8 ). Therefore, we can conclude that there is a very high correlation (closeness) between the proposed FRSA-MSWSPII model and the other models for the treatment of uncertainty (fuzzy and rough), especially when the number of synthesized weights is more than 4 .

5.2. Sensitivity Analysis. Since the results of MCDM models depend to a great extent on the values of the weight coefficients of the assessment index, this section shows 
TABLe 17: Comparison of the ranks of alternatives according to models 1, 6, and 7 .

\begin{tabular}{|c|c|c|c|c|c|c|c|c|c|c|c|c|c|}
\hline & \multirow{2}{*}{ Model 1} & \multicolumn{6}{|c|}{ Model 6} & \multicolumn{6}{|c|}{ Model 7} \\
\hline & & 2.1 & 2.2 & 2.3 & 2.4 & 2.5 & 2.6 & 3.1 & 3.2 & 3.3 & 3.4 & 3.5 & 3.6 \\
\hline Alter. 1 & 4 & 7 & 6 & 5 & 5 & 4 & 4 & 7 & 7 & 4 & 3 & 4 & 4 \\
\hline Alter. 2 & 2 & 2 & 2 & 2 & 2 & 2 & 2 & 1 & 1 & 1 & 1 & 1 & 2 \\
\hline Alter. 3 & 1 & 1 & 1 & 1 & 1 & 1 & 1 & 4 & 2 & 2 & 5 & 2 & 1 \\
\hline Alter. 4 & 5 & 3 & 3 & 7 & 6 & 5 & 5 & 2 & 3 & 8 & 8 & 6 & 6 \\
\hline Alter. 5 & 10 & 8 & 9 & 10 & 10 & 9 & 9 & 9 & 10 & 9 & 9 & 10 & 10 \\
\hline Alter. 6 & 6 & 6 & 7 & 4 & 4 & 7 & 7 & 5 & 5 & 3 & 2 & 5 & 5 \\
\hline Alter. 7 & 8 & 9 & 8 & 6 & 7 & 8 & 8 & 10 & 9 & 6 & 7 & 9 & 9 \\
\hline Alter. 8 & 3 & 4 & 4 & 3 & 3 & 3 & 3 & 3 & 4 & 7 & 4 & 3 & 3 \\
\hline Alter. 9 & 7 & 5 & 5 & 8 & 9 & 6 & 6 & 6 & 6 & 10 & 10 & 7 & 7 \\
\hline Alter. 10 & 9 & 10 & 10 & 9 & 8 & 10 & 10 & 8 & 8 & 5 & 6 & 8 & 8 \\
\hline
\end{tabular}

TABLE 18: Comparison of the ranks of alternatives according to models 1,8 , and 9.

\begin{tabular}{|c|c|c|c|c|c|c|c|c|c|c|c|c|c|}
\hline & \multirow{2}{*}{ Model 1} & \multicolumn{6}{|c|}{ Model 8} & \multicolumn{6}{|c|}{ Model 9} \\
\hline & & 2.1 & 2.2 & 2.3 & 2.4 & 2.5 & 2.6 & 3.1 & 3.2 & 3.3 & 3.4 & 3.5 & 3.6 \\
\hline Alter. 1 & 4 & 5 & 4 & 4 & 6 & 5 & 4 & 4 & 4 & 4 & 6 & 4 & 4 \\
\hline Alter. 2 & 2 & 2 & 2 & 2 & 2 & 2 & 2 & 1 & 1 & 1 & 1 & 1 & 1 \\
\hline Alter. 3 & 1 & 1 & 1 & 1 & 1 & 1 & 1 & 3 & 2 & 2 & 2 & 2 & 2 \\
\hline Alter. 4 & 5 & 6 & 6 & 6 & 3 & 6 & 5 & 6 & 6 & 6 & 3 & 7 & 6 \\
\hline Alter. 5 & 10 & 9 & 9 & 9 & 9 & 10 & 9 & 9 & 10 & 10 & 10 & 10 & 10 \\
\hline Alter. 6 & 6 & 4 & 5 & 5 & 7 & 4 & 6 & 5 & 5 & 5 & 5 & 3 & 5 \\
\hline Alter. 7 & 8 & 8 & 8 & 8 & 8 & 7 & 8 & 10 & 9 & 9 & 9 & 8 & 9 \\
\hline Alter. 8 & 3 & 3 & 3 & 3 & 4 & 3 & 3 & 2 & 3 & 3 & 4 & 6 & 3 \\
\hline Alter. 9 & 7 & 7 & 7 & 7 & 5 & 8 & 7 & 7 & 7 & 7 & 7 & 9 & 7 \\
\hline Alter. 10 & 9 & 10 & 10 & 10 & 10 & 9 & 10 & 8 & 8 & 8 & 8 & 5 & 8 \\
\hline
\end{tabular}

TABLE 19: Comparison of the ranks of alternatives according to models 1, 10, and 11.

\begin{tabular}{lccc}
\hline & Model 1 & Model 10 & Model 11 \\
\hline Alter. 1 & 4 & 4 & 3 \\
Alter. 2 & 2 & 2 & 2 \\
Alter. 3 & 1 & 1 & 1 \\
Alter. 4 & 5 & 6 & 5 \\
Alter. 5 & 10 & 10 & 10 \\
Alter. 6 & 6 & 5 & 4 \\
Alter. 7 & 8 & 8 & 9 \\
Alter. 8 & 3 & 3 & 8 \\
Alter. 9 & 7 & 7 & 7 \\
Alter. 10 & 9 & 9 & 8 \\
\hline
\end{tabular}

TABLe 20: Correlation of the ranks in the models 1, 2, and 3.

\begin{tabular}{lccccccccccccc}
\hline & Model & Model & Model & Model & Model & Model & Model & Model & Model & Model & Model & Model & Model \\
& 1 & 2.1 & 2.2 & 2.3 & 2.4 & 2.5 & 2.6 & 3.1 & 3.2 & 3.3 & 3.4 & 3.5 & 3.6 \\
\hline $\begin{array}{l}\text { Model } 1 \\
\text { Model }\end{array}$ & 1 & 0.78 & 0.78 & 0.88 & 0.90 & 0.90 & 0.94 & 0.76 & 0.79 & 0.38 & 0.58 & 0.77 & 0.71 \\
$\begin{array}{l}2.1 \\
\text { Model }\end{array}$ & - & 1 & 1 & 0.61 & 0.68 & 0.48 & 0.59 & 0.87 & 0.90 & 0.21 & 0.35 & 0.32 & 0.27 \\
$\begin{array}{l}2.2 \\
\text { Model }\end{array}$ & - & - & 1 & 0.61 & 0.68 & 0.48 & 0.59 & 0.87 & 0.90 & 0.21 & 0.35 & 0.32 & 0.27 \\
$\begin{array}{l}2.3 \\
\text { Model }\end{array}$ & - & - & - & 1 & 0.99 & 0.83 & 0.84 & 0.79 & 0.78 & 0.67 & 0.84 & 0.73 & 0.67 \\
2.4 & - & - & - & - & 1 & 0.82 & 0.85 & 0.84 & 0.83 & 0.65 & 0.79 & 0.72 & 0.66 \\
\hline
\end{tabular}


Table 20: Continued.

\begin{tabular}{|c|c|c|c|c|c|c|c|c|c|c|c|c|c|}
\hline & $\begin{array}{c}\text { Model } \\
1 \\
\end{array}$ & $\begin{array}{c}\text { Model } \\
2.1 \\
\end{array}$ & $\begin{array}{c}\text { Model } \\
2.2 \\
\end{array}$ & $\begin{array}{c}\text { Model } \\
2.3\end{array}$ & $\begin{array}{c}\text { Model } \\
2.4\end{array}$ & $\begin{array}{c}\text { Model } \\
2.5\end{array}$ & $\begin{array}{c}\text { Model } \\
2.6\end{array}$ & $\begin{array}{c}\text { Model } \\
3.1\end{array}$ & $\begin{array}{c}\text { Model } \\
3.2 \\
\end{array}$ & $\begin{array}{c}\text { Model } \\
3.3 \\
\end{array}$ & $\begin{array}{c}\text { Model } \\
3.4\end{array}$ & $\begin{array}{c}\text { Model } \\
3.5 \\
\end{array}$ & $\begin{array}{c}\text { Model } \\
3.6 \\
\end{array}$ \\
\hline $\begin{array}{l}\text { Model } \\
2.5\end{array}$ & - & - & - & - & - & 1 & 0.98 & 0.47 & 0.50 & 0.32 & 0.59 & 0.88 & 0.83 \\
\hline $\begin{array}{l}\text { Model } \\
2.6\end{array}$ & - & - & - & - & - & - & 1 & 0.58 & 0.60 & 0.31 & 0.56 & 0.89 & 0.85 \\
\hline $\begin{array}{l}\text { Model } \\
3.1\end{array}$ & - & - & - & - & - & - & - & 1 & 0.99 & 0.59 & 0.61 & 0.38 & 0.33 \\
\hline $\begin{array}{l}\text { Model } \\
3.2\end{array}$ & - & - & - & - & - & - & - & - & 1 & 0.55 & 0.56 & 0.37 & 0.31 \\
\hline $\begin{array}{l}\text { Model } \\
3.3\end{array}$ & - & - & - & - & - & - & - & - & - & 1 & 0.77 & 0.14 & 0.09 \\
\hline $\begin{array}{l}\text { Model } \\
3.4\end{array}$ & - & - & - & - & - & - & - & - & - & - & 1 & 0.49 & 0.48 \\
\hline $\begin{array}{l}\text { Model } \\
3.5\end{array}$ & - & - & - & - & - & - & - & - & - & - & - & 1 & 0.99 \\
\hline $\begin{array}{l}\text { Model } \\
3.6\end{array}$ & - & - & - & - & - & - & - & - & - & - & - & - & 1 \\
\hline
\end{tabular}

TABLE 21: Correlation of the ranks in the models 1, 4, and 5.

\begin{tabular}{|c|c|c|c|c|c|c|c|c|c|c|c|c|c|}
\hline & $\begin{array}{c}\text { Model } \\
1\end{array}$ & $\begin{array}{c}\text { Model } \\
4.1\end{array}$ & $\begin{array}{c}\text { Model } \\
4.2\end{array}$ & $\begin{array}{c}\text { Model } \\
4.3\end{array}$ & $\begin{array}{c}\text { Model } \\
4.4\end{array}$ & $\begin{array}{l}\text { Model } \\
4.5\end{array}$ & $\begin{array}{c}\text { Model } \\
4.6\end{array}$ & $\begin{array}{c}\text { Model } \\
5.1\end{array}$ & $\begin{array}{l}\text { Model } \\
5.2\end{array}$ & $\begin{array}{c}\text { Model } \\
5.3\end{array}$ & $\begin{array}{c}\text { Model } \\
5.4\end{array}$ & $\begin{array}{c}\text { Model } \\
5.5\end{array}$ & $\begin{array}{c}\text { Model } \\
5.6\end{array}$ \\
\hline Model 1 & 1 & 0.85 & 0.88 & 0.98 & 0.83 & 0.92 & 0.93 & 0.81 & 0.56 & 0.98 & 0.85 & 0.71 & 0.82 \\
\hline $\begin{array}{l}\text { Model } \\
4.1\end{array}$ & - & 1 & 0.62 & 0.89 & 0.98 & 0.85 & 0.66 & 0.92 & 0.24 & 0.81 & 0.94 & 0.64 & 0.49 \\
\hline $\begin{array}{l}\text { Model } \\
4.2\end{array}$ & - & - & 1 & 0.79 & 0.53 & 0.88 & 0.93 & 0.59 & 0.75 & 0.89 & 0.66 & 0.73 & 0.90 \\
\hline $\begin{array}{l}\text { Model } \\
4.3\end{array}$ & - & - & - & 1 & 0.89 & 0.85 & 0.88 & 0.78 & 0.45 & 0.93 & 0.83 & 0.58 & 0.72 \\
\hline $\begin{array}{l}\text { Model } \\
4.4\end{array}$ & - & - & - & - & 1 & 0.78 & 0.64 & 0.87 & 0.15 & 0.77 & 0.89 & 0.55 & 0.45 \\
\hline $\begin{array}{l}\text { Model } \\
4.5\end{array}$ & - & - & - & - & - & 1 & 0.87 & 0.84 & 0.62 & 0.93 & 0.89 & 0.84 & 0.81 \\
\hline $\begin{array}{l}\text { Model } \\
4.6\end{array}$ & - & - & - & - & - & - & 1 & 0.59 & 0.72 & 0.92 & 0.66 & 0.67 & 0.95 \\
\hline $\begin{array}{l}\text { Model } \\
5.1\end{array}$ & - & - & - & - & - & - & - & 1 & 0.35 & 0.79 & 0.99 & 0.76 & 0.48 \\
\hline $\begin{array}{l}\text { Model } \\
5.2\end{array}$ & - & - & - & - & - & - & - & - & 1 & 0.62 & 0.38 & 0.49 & 0.77 \\
\hline $\begin{array}{l}\text { Model } \\
5.3\end{array}$ & - & - & - & - & - & - & - & - & - & 1 & 0.85 & 0.76 & 0.85 \\
\hline $\begin{array}{l}\text { Model } \\
5.4\end{array}$ & - & - & - & - & - & - & - & - & - & - & 1 & 0.79 & 0.56 \\
\hline $\begin{array}{l}\text { Model } \\
5.5\end{array}$ & - & - & - & - & - & - & - & - & - & - & - & 1 & 0.75 \\
\hline $\begin{array}{l}\text { Model } \\
5.6\end{array}$ & - & - & - & - & - & - & - & - & - & - & - & - & 1 \\
\hline
\end{tabular}

sensitivity analysis of the results when there is a change in the weights of the assessment index.

Sometimes the ranks of the alternatives change as a result of very small changes in the weight coefficients. Therefore, the results of MCDM models as a rule are accompanied by an analysis of their sensitivity to these changes. This section presents a sensitivity analysis of the ranking of the alternatives to changes in the weight coefficients of the assessment index carried out through 27 scenarios (Tables 25-27).

The scenarios for the sensitivity analysis were grouped into three phases. In each phase of the sensitivity analysis, the weight coefficients of the assessment index are increased, respectively, by $25 \%, 50 \%$, and $75 \%$. One assessment index is favoured per scenario for each of nine scenarios in the phase, and its weight coefficient is increased by the given values. In the same scenario, the weight coefficients of the remaining assessment index were each reduced by the corresponding ratios. Changes in the ranking of the alternatives for the scenarios are shown in Tables 25-27.

The results (Tables 25-27) show that the allocation of different weights to the assessment index through the scenarios leads to a change in the ranking of the alternatives, 
TABle 22: Correlation of the ranks in the models 1, 6, and 7.

\begin{tabular}{|c|c|c|c|c|c|c|c|c|c|c|c|c|c|}
\hline & $\begin{array}{c}\text { Model } \\
1\end{array}$ & $\begin{array}{c}\text { Model } \\
6.1\end{array}$ & $\begin{array}{c}\text { Model } \\
6.2\end{array}$ & $\begin{array}{c}\text { Model } \\
6.3\end{array}$ & $\begin{array}{c}\text { Model } \\
6.4\end{array}$ & $\begin{array}{c}\text { Model } \\
6.5\end{array}$ & $\begin{array}{c}\text { Model } \\
6.6\end{array}$ & $\begin{array}{c}\text { Model } \\
7.1\end{array}$ & $\begin{array}{c}\text { Model } \\
7.2\end{array}$ & $\begin{array}{c}\text { Model } \\
7.3\end{array}$ & $\begin{array}{c}\text { Model } \\
7.4\end{array}$ & $\begin{array}{c}\text { Model } \\
7.5\end{array}$ & $\begin{array}{c}\text { Model } \\
7.6\end{array}$ \\
\hline Model 1 & 1 & 0.85 & 0.90 & 0.92 & 0.93 & 0.98 & 0.98 & 0.78 & 0.88 & 0.60 & 0.61 & 0.96 & 0.98 \\
\hline $\begin{array}{l}\text { Model } \\
6.1\end{array}$ & - & 1 & 0.98 & 0.71 & 0.72 & 0.89 & 0.89 & 0.88 & 0.93 & 0.31 & 0.27 & 0.79 & 0.81 \\
\hline $\begin{array}{l}\text { Model } \\
6.2\end{array}$ & - & - & 1 & 0.75 & 0.75 & 0.94 & 0.94 & 0.84 & 0.92 & 0.33 & 0.28 & 0.82 & 0.83 \\
\hline $\begin{array}{l}\text { Model } \\
6.3\end{array}$ & - & - & - & 1 & 0.98 & 0.85 & 0.85 & 0.62 & 0.77 & 0.75 & 0.75 & 0.90 & 0.92 \\
\hline $\begin{array}{l}\text { Model } \\
6.4\end{array}$ & - & - & - & - & 1 & 0.84 & 0.84 & 0.70 & 0.82 & 0.78 & 0.78 & 0.93 & 0.94 \\
\hline $\begin{array}{l}\text { Model } \\
6.5\end{array}$ & - & - & - & - & - & 1 & 1 & 0.76 & 0.84 & 0.47 & 0.48 & 0.92 & 0.93 \\
\hline $\begin{array}{l}\text { Model } \\
6.6\end{array}$ & - & - & - & - & - & - & 1 & 0.76 & 0.84 & 0.47 & 0.48 & 0.92 & 0.93 \\
\hline $\begin{array}{l}\text { Model } \\
7.1\end{array}$ & - & - & - & - & - & - & - & 1 & 0.95 & 0.33 & 0.44 & 0.81 & 0.77 \\
\hline $\begin{array}{l}\text { Model } \\
7.2\end{array}$ & - & - & - & - & - & - & - & - & 1 & 0.50 & 0.49 & 0.88 & 0.87 \\
\hline $\begin{array}{l}\text { Model } \\
7.3\end{array}$ & - & - & - & - & - & - & - & - & - & 1 & 0.87 & 0.68 & 0.67 \\
\hline $\begin{array}{l}\text { Model } \\
7.4\end{array}$ & - & - & - & - & - & - & - & - & - & - & 1 & 0.75 & 0.70 \\
\hline $\begin{array}{l}\text { Model } \\
7.5\end{array}$ & - & - & - & - & - & - & - & - & - & - & - & 1 & 0.99 \\
\hline $\begin{array}{l}\text { Model } \\
7.6\end{array}$ & - & - & - & - & - & - & - & - & - & - & - & - & 1 \\
\hline
\end{tabular}

TABLE 23: Correlation of the ranks in the models 1,8 , and 9.

\begin{tabular}{|c|c|c|c|c|c|c|c|c|c|c|c|c|c|}
\hline & $\begin{array}{c}\text { Model } \\
1\end{array}$ & $\begin{array}{c}\text { Model } \\
8.1\end{array}$ & $\begin{array}{c}\text { Model } \\
8.2\end{array}$ & $\begin{array}{c}\text { Model } \\
8.3\end{array}$ & $\begin{array}{c}\text { Model } \\
8.4\end{array}$ & $\begin{array}{c}\text { Model } \\
8.5\end{array}$ & $\begin{array}{c}\text { Model } \\
8.6\end{array}$ & $\begin{array}{c}\text { Model } \\
9.1\end{array}$ & $\begin{array}{c}\text { Model } \\
9.2\end{array}$ & $\begin{array}{c}\text { Model } \\
9.3\end{array}$ & $\begin{array}{l}\text { Model } \\
9.4\end{array}$ & $\begin{array}{l}\text { Model } \\
9.5\end{array}$ & $\begin{array}{c}\text { Model } \\
9.6\end{array}$ \\
\hline Model 1 & 1 & 0.95 & 0.98 & 0.98 & 0.90 & 0.95 & 0.99 & 0.92 & 0.96 & 0.96 & 0.92 & 0.73 & 0.96 \\
\hline $\begin{array}{l}\text { Model } \\
8.1\end{array}$ & - & 1 & 0.99 & 0.99 & 0.85 & 0.98 & 0.96 & 0.90 & 0.94 & 0.94 & 0.88 & 0.73 & 0.94 \\
\hline $\begin{array}{l}\text { Model } \\
8.2\end{array}$ & - & - & 1 & 1 & 0.87 & 0.96 & 0.99 & 0.92 & 0.95 & 0.95 & 0.87 & 0.72 & 0.95 \\
\hline $\begin{array}{l}\text { Model } \\
8.3\end{array}$ & - & - & - & 1 & 0.87 & 0.96 & 0.99 & 0.92 & 0.95 & 0.95 & 0.87 & 0.72 & 0.95 \\
\hline $\begin{array}{l}\text { Model } \\
8.4\end{array}$ & - & - & - & - & 1 & 0.81 & 0.92 & 0.77 & 0.82 & 0.82 & 0.90 & 0.49 & 0.82 \\
\hline $\begin{array}{l}\text { Model } \\
8.5\end{array}$ & - & - & - & - & - & 1 & 0.94 & 0.88 & 0.94 & 0.94 & 0.88 & 0.81 & 0.94 \\
\hline $\begin{array}{l}\text { Model } \\
8.6\end{array}$ & - & - & - & - & - & - & 1 & 0.90 & 0.94 & 0.94 & 0.89 & 0.67 & 0.94 \\
\hline $\begin{array}{l}\text { Model } \\
9.1\end{array}$ & - & - & - & - & - & - & - & 1 & 0.98 & 0.98 & 0.88 & 0.76 & 0.98 \\
\hline $\begin{array}{l}\text { Model } \\
9.2\end{array}$ & - & - & - & - & - & - & - & - & 1 & 1 & 0.92 & 0.83 & 1 \\
\hline $\begin{array}{l}\text { Model } \\
9.3\end{array}$ & - & - & - & - & - & - & - & - & - & 1 & 0.92 & 0.83 & 1 \\
\hline $\begin{array}{l}\text { Model } \\
9.4\end{array}$ & - & - & - & - & - & - & - & - & - & - & 1 & 0.75 & 0.92 \\
\hline $\begin{array}{l}\text { Model } \\
9.5\end{array}$ & - & - & - & - & - & - & - & - & - & - & - & 1 & 0.83 \\
\hline $\begin{array}{l}\text { Model } \\
9.6\end{array}$ & - & - & - & - & - & - & - & - & - & - & - & - & 1 \\
\hline
\end{tabular}


TABLE 24: Correlation of the ranks in the models 1,10 , and 11 .

\begin{tabular}{lccc}
\hline & Model 1 & Model 10 & Model 11 \\
\hline Model 1 & 1 & 0.99 & 0.88 \\
Model 10 & - & 1 & 0.89 \\
Model 11 & - & - & 1 \\
\hline
\end{tabular}

TABle 25: Scenarios for the sensitivity analysis (phase I, 25\%).

\begin{tabular}{|c|c|c|c|c|c|c|c|c|c|}
\hline & $t w_{1} * 1.25$ & $t w_{2} * 1.25$ & $t w_{3} * 1.25$ & $t w_{4} * 1.25$ & $t w_{5} * 1.25$ & $t w_{6} * 1.25$ & $t w_{7} * 1.25$ & $t w_{8} * 1.25$ & $t w_{9} * 1.25$ \\
\hline Alter. 1 & 4 & 4 & 3 & 8 & 3 & 3 & 5 & 7 & 4 \\
\hline Alter. 2 & 2 & 2 & 2 & 3 & 2 & 1 & 1 & 1 & 2 \\
\hline Alter. 3 & 1 & 1 & 1 & 1 & 1 & 2 & 2 & 2 & 1 \\
\hline Alter. 4 & 5 & 5 & 4 & 5 & 8 & 5 & 4 & 3 & 7 \\
\hline Alter. 5 & 10 & 10 & 9 & 10 & 6 & 7 & 10 & 5 & 10 \\
\hline Alter. 6 & 6 & 7 & 5 & 2 & 4 & 8 & 3 & 8 & 5 \\
\hline Alter. 7 & 8 & 8 & 7 & 9 & 5 & 6 & 7 & 9 & 6 \\
\hline Alter. 8 & 3 & 3 & 8 & 4 & 7 & 4 & 6 & 6 & 3 \\
\hline Alter. 9 & 7 & 6 & 6 & 7 & 9 & 9 & 8 & 4 & 8 \\
\hline Alter. 10 & 9 & 9 & 10 & 6 & 10 & 10 & 9 & 10 & 9 \\
\hline
\end{tabular}

TABLe 26: Scenarios for the sensitivity analysis (phase I, 50\%).

\begin{tabular}{|c|c|c|c|c|c|c|c|c|c|}
\hline & $t w_{1} * 1.50$ & $t w_{2} * 1.50$ & $t w_{3} * 1.50$ & $t w_{4} * 1.50$ & $t w_{5} * 1.50$ & $t w_{6} * 1.50$ & $t w_{7} * 1.50$ & $t w_{8} * 1.50$ & $t w_{9} * 1.50$ \\
\hline Alter. 1 & 4 & 4 & 3 & 8 & 3 & 4 & 6 & 7 & 4 \\
\hline Alter. 2 & 2 & 1 & 2 & 5 & 2 & 1 & 1 & 1 & 2 \\
\hline Alter. 3 & 1 & 2 & 1 & 1 & 1 & 2 & 2 & 2 & 1 \\
\hline Alter. 4 & 5 & 5 & 4 & 4 & 7 & 5 & 4 & 3 & 7 \\
\hline Alter. 5 & 10 & 10 & 9 & 10 & 5 & 7 & 10 & 5 & 10 \\
\hline Alter. 6 & 6 & 8 & 7 & 2 & 4 & 8 & 3 & 8 & 5 \\
\hline Alter. 7 & 8 & 7 & 6 & 9 & 6 & 6 & 7 & 9 & 6 \\
\hline Alter. 8 & 3 & 3 & 8 & 3 & 8 & 3 & 5 & 6 & 3 \\
\hline Alter. 9 & 7 & 6 & 5 & 7 & 9 & 9 & 8 & 4 & 8 \\
\hline Alter. 10 & 9 & 9 & 10 & 6 & 10 & 10 & 9 & 10 & 9 \\
\hline
\end{tabular}

TABLE 27: Scenarios for the sensitivity analysis (phase I, 75\%).

\begin{tabular}{|c|c|c|c|c|c|c|c|c|c|}
\hline & $t w_{1} * 1.75$ & $t w_{2} * 1.75$ & $t w_{3} * 1.75$ & $t w_{4} * 1.75$ & $t w_{5} * 1.75$ & $t w_{6} * 1.75$ & $t w_{7} * 1.75$ & $t w_{8} * 1.75$ & $t w_{9} * 1.75$ \\
\hline Alter. 1 & 4 & 4 & 3 & 8 & 3 & 4 & 6 & 8 & 4 \\
\hline Alter. 2 & 2 & 1 & 2 & 6 & 2 & 1 & 1 & 1 & 2 \\
\hline Alter. 3 & 1 & 2 & 1 & 1 & 1 & 2 & 2 & 2 & 1 \\
\hline Alter. 4 & 5 & 6 & 4 & 3 & 7 & 5 & 5 & 3 & 8 \\
\hline Alter. 5 & 10 & 10 & 9 & 10 & 5 & 7 & 10 & 5 & 10 \\
\hline Alter. 6 & 6 & 8 & 7 & 2 & 4 & 8 & 3 & 7 & 5 \\
\hline Alter. 7 & 8 & 7 & 6 & 9 & 6 & 6 & 8 & 9 & 6 \\
\hline Alter. 8 & 3 & 3 & 8 & 4 & 8 & 3 & 4 & 6 & 3 \\
\hline Alter. 9 & 7 & 5 & 5 & 7 & 9 & 9 & 7 & 4 & 7 \\
\hline Alter. 10 & 9 & 9 & 10 & 5 & 10 & 10 & 9 & 10 & 9 \\
\hline
\end{tabular}

TABLE 28: Correlations in the ranking of 27 scenarios.

\begin{tabular}{|c|c|c|c|c|c|}
\hline Scenario & SCC & Scenario & SCC & Scenario & SCC \\
\hline S1 & 1.00 & $\mathrm{~S} 10$ & 1.00 & S19 & 1.00 \\
\hline S2 & 0.99 & S11 & 0.95 & $\mathrm{~S} 20$ & 0.93 \\
\hline S3 & 0.81 & S12 & 0.77 & S21 & 0.77 \\
\hline S4 & 0.73 & S13 & 0.68 & $\mathrm{~S} 22$ & 0.58 \\
\hline S5 & 0.64 & S14 & 0.59 & $\mathrm{~S} 23$ & 0.59 \\
\hline S6 & 0.84 & S15 & 0.85 & $\mathrm{~S} 24$ & 0.85 \\
\hline S7 & 0.85 & S16 & 0.87 & $\mathrm{~S} 25$ & 0.90 \\
\hline S8 & 0.61 & S17 & 0.61 & S26 & 0.59 \\
\hline S9 & 0.94 & S18 & 0.94 & S27 & 0.92 \\
\hline
\end{tabular}


which confirms that the model is sensitive to changes in the weight coefficients. By comparing the alternatives which are ranked first (Alter. 3 and Alter. 2) in scenarios 1-27 with the initial ranking (Table 14), it is can be seen that the rank of the highest ranked alternative is confirmed. Analyzing the ranking through 27 scenarios also shows that alternative Alter. 3 holds its rank in 16 scenarios, while in 11 scenarios, it is ranked second. The alternative ranked second (Alter. 2) holds its rank in 13 scenarios, while it is ranked first in 11 scenarios. Changing the weights of the assessment indexes through the scenarios leads to changes in the ranking of the remaining alternatives. However, these changes were not drastic, which also confirms the correlation of the ranks through the scenarios (Table 28).

The SCC values were obtained by comparing the initial ranks of the FRSA-MSWS-PII model (Table 14) with those obtained through the scenarios (Tables 25-27). By analyzing the results (Table 28), we can conclude that there is a high correlation of the ranks, since in 15 scenarios, the value of SCC is greater than 0.80 , while in the remaining scenarios, it is greater than 0.55 . The average value of SCC through all the scenarios is 0.81 , which indicates a high average correlation. On this basis, we can conclude that there is satisfactory closeness of the ranks and that the proposed ranking is confirmed and credible.

\section{Conclusions}

In future manufacturing industry, there is no doubt about that green intelligent manufacturing is the target direction of sustainable development. The key point of green intelligent manufacturing is to achieve a reasonable balance of environmental, social, and economic performance of manufacturing system and a sustainable development of consumption and production. Obviously, some technical and policy support are required. Driven by digital twin system, this paper focuses on the methodology from the perspective of green performance evaluation of intelligent manufacturing to promote the transformation of manufacturing industry to green intelligent manufacturing.

Because the contribution in this paper is just a pilot study on the social influence evaluation for intelligent manufacturing, there are many future works that should be carried out in the future. It is only a performance evaluation model based on MCDM, and the mechanism that how multiple factors affect the green performance of intelligent manufacturing has not been studied deeply. In addition, the development of intelligent manufacturing will pay more attention to the impact on people in the future. In the final analysis, whether intelligent manufacturing can provide human with a well-being work and comfortable life will be explored. Human-oriented green performance evaluation methodology of intelligent manufacturing is necessary to study in the future. For example, the long-term and cumulative impact of intelligent manufacturing on human beings should be evaluated with the coordination of intelligence and economy of intelligent manufacturing. Then, a green maturity model of intelligent manufacturing in the whole life cycle can be built based on the decision-making support from the green performance evaluation.

\section{Data Availability}

The data used to support the findings of this study are available from the corresponding author upon request.

\section{Conflicts of Interest}

The authors declare that there are no conflicts of interest.

\section{Authors' Contributions}

Lianhui Li and Bingbing Lei are the principal investigators of the study. Bingbing Lei assisted Lianhui Li to propose the novel hybrid model. Chunlei Mao and Hongxia Sun designed the case study and checked the manuscript. Yiping Yuan processed the data and did the data analysis work in the case study.

\section{Acknowledgments}

The authors thank assistant editor for the useful suggestions which improve the quality of this research. This research was funded by The Third Batch of Ningxia Youth Talents Supporting Project (TGJC2018048), Ningxia Natural Science Foundation (NZ17111 and 2020AAC03202), National Natural Science Foundation of China (51875251), Guangdong Special Support Talent Program-Innovation and Entrepreneurship Leading Team (2019BT02S593), National Key Research and Development Plan (2019YFB2102000), and Youth Project with Special Fund for Basic Scientific Research Business Expenses of Central Level Public Welfare Scientific Research Institutes (Y919008).

\section{References}

[1] H. Feng, L. Xi, L. Xiao, T. Xia, and E. Pan, "Imperfect preventive maintenance optimization for flexible flowshop manufacturing cells considering sequence-dependent group scheduling," Reliability Engineering \& System Safety, vol. 176, pp. 218-229, 2018.

[2] G. Mejía and J. Pereira, "Multiobjective scheduling algorithm for flexible manufacturing systems with Petri nets," Journal of Manufacturing Systems, vol. 54, pp. 272-284, 2020.

[3] J. Delaram and O. F. Valilai, "An architectural solution for virtual computer integrated manufacturing systems using ISO standards," Scientia Iranica, vol. 26, no. 6, pp. 3712-3727, 2018.

[4] Q. Guo and M. Zhang, "A novel approach for multi-agentbased Intelligent Manufacturing System," Information Sciences, vol. 179, no. 18, pp. 3079-3090, 2009.

[5] A. Simeone, "Resource efficiency optimization engine in smart production networks via intelligent cloud manufacturing platforms," Procedia Cirp, vol. 78, pp. 19-24, 2018.

[6] S. Ren, Y. Zhang, Y. Liu, T. Sakao, D. Huisingh, and C. M. V. B. Almeida, "A comprehensive review of big data analytics throughout product lifecycle to support sustainable smart manufacturing: a framework, challenges and future research directions," Journal of Cleaner Production, vol. 210, pp. 1343-1365, 2019. 
[7] S. Wang, W. D. Liang, and X. T. Cai, "Big data enabled intelligent immune system for energy efficient manufacturing management," Journal of Cleaner Production, vol. 195, no. 9, pp. 507-520, 2018.

[8] T. F. Edgar and E. N. Pistikopoulos, "Smart manufacturing and energy systems," Computers \& Chemical Engineering, vol. 114, pp. 130-144, 2018.

[9] S. Jia, R. Tang, and J. Lv, “Therblig-based energy demand modeling methodology of machining process to support intelligent manufacturing," Journal of Intelligent Manufacturing, vol. 25, no. 5, 2014.

[10] K.-D. Thoben, S. Wiesner, and S. T. Wiesner, "Industrie 4.0 and smart manufacturing-a review of research issues and application examples," International Journal of Automation Technology, vol. 11, no. 1, pp. 4-16, 2017.

[11] A. Wuest, "Fundamentals of smart manufacturing: a multithread perspective," Annual Reviews in Control, vol. 47, pp. 214-220, 2019.

[12] B. Gong, "The discussion on evaluation index and the assessment method of intelligent manufacturing," Application of Electronic Technique, vol. 41, no. 11, pp. 6-8, 2015.

[13] J. Y. Jia and J. Shi, "Review on middle managers performance appraisal," in Proceedings of the International Conference on Education, Management, Arts, Economics and Social Science, vol. 1, Atlantis Press, Paris, France, pp. 695-700, 2016.

[14] W. Yi, Pe. Dong, and J. Wang, "Research on evaluation model of enterpri es intelligent manufacturing capacity based on high order tensor analysis," Industrial Technology \& Economy, vol. 37, no. 1, pp. 11-16, 2018.

[15] D. Xue-hong, S. Li, L. I. Min et al., "Research on intelligent manufacturing capability maturity evaluation based on BP neural network," Journal of Qingdao University (Natural Science Edition), vol. 32, no. 3, pp. 20-25, 2019.

[16] Y. Qu, Y. Shi, K. Guo, and Y. Zheng, "Has "intelligent manufacturing" promoted the productivity of manufacturing sector?--evidence from China's listed firms," Procedia Computer Science, vol. 139, pp. 299-305, 2018.

[17] A. Schumacher, W. S. Erol, and W. Sihn, "A maturity model for assessing industry 4.0 readiness and maturity of manufacturing enterprises," Procedia CIRP, vol. 52, pp. 161-166, 2016.

[18] K. Jung, K. W. Morris, S. Leong, and H. Cho, "Mapping strategic goals and operational performance metrics for smart manufacturing systems," Procedia Computer Science, vol. 44, pp. 184-193, 2015.

[19] A. R. Mashhadi and S. Behdad, "Ubiquitous life cycle assessment (U-LCA): a proposed concept for environmental and social impact assessment of industry 4.0," Manufacturing Letters, vol. 15, pp. 93-96, 2018.

[20] M. Peruzzini, F. Gregori, A. Luzi, M. Mengarelli, and M. Germani, "A social life cycle assessment methodology for smart manufacturing: the case of study of a kitchen sink," Journal of Industrial Information Integration, vol. 7, pp. 2432, 2017

[21] K. Zhang, T. Qu, D. Zhou, H. Jiang, and Y. Lin, "Digital twinbased opti-state control method for a synchronized production operation system," Robotics and Computer-Integrated Manufacturing, vol. 63, no. 11, pp. 1-15, 2019.

[22] J. Leng, D. Yan, Q. Liu* et al., "Digital twin-driven joint optimization of packing and storage assignment in large-scale automated high-rise warehouse," International Journal of Computer Integrated Manufacturing, vol. 21, no. 8, pp. 2490-2509, 2019.

[23] F. Meng, H. J. Tang, and H. Fujita, "Linguistic intuitionistic fuzzy preference relations and their application to multi- criteria decision making," Information Fusion, vol. 46, pp. 77-90, 2019.

[24] Y. Qin, X. Cui, M. Huang et al., "Archimedean muirhead aggregation operators of q-rung orthopair fuzzy numbers for multicriteria group decision making," Complexity, vol. 2019, Article ID 3103741, 33 pages, 2019.

[25] F. Meng and X. Chen, "Interval-valued intuitionistic fuzzy multi-criteria group decision making based on cross entropy and 2-additive measures," Soft Computing, vol. 19, no. 7, pp. 2071-2082, 2015.

[26] T.-L. Nguyen, "Methods in ranking fuzzy numbers: a unified index and comparative reviews," Complexity, vol. 2017, Article ID 3083745, 13 pages, 2017.

[27] L.-Y. Li, J.-C. Hang, Y. Gao, and C. Y. Mu, "Using an integrated group decision method based on SVM, TFN-RS-AHP, and TOPSIS-CD for cloud service supplier selection," Mathematical Problems in Engineering, vol. 2017, Article ID 3143502, 14 pages, 2017.

[28] L. H. Li, J. C. Hang, H. X. Sun, and L. Wang, "A conjunctive multiple-criteria decision-making approach for cloud service supplier selection of manufacturing enterprise," Advances in Mechanical Engineering, vol. 9, no. 3, pp. 1-15, 2017.

[29] W. Yang and Y. Pang, "Hesitant interval-valued pythagorean fuzzy VIKOR method," International Journal of Intelligent Systems, vol. 34, no. 5, pp. 754-789, 2019.

[30] H. J. Zhang, Y. Zhou, and Q. H. Gan, "An extended PROMETHEE-II-based risk prioritization method for equipment failures in the geothermal power plant," International Journal of Fuzzy Systems, vol. 2, no. 8, pp. 2490-2509, 2019.

[31] Pamučar, "Novel approach to group multi-criteria decision making based on interval rough numbers: hybrid DEMATELANP-MAIRCA model," Expert Systems with Application, vol. 88, pp. 58-80, 2017.

[32] D. Pamučar, I. Petrovic, and G. Cirovic, "Modification of the Best-Worst and MABAC methods: a novel approach based on interval-valued fuzzy-rough numbers," Expert Systems with Application, vol. 91, pp. 89-106, 2018.

[33] M. K. Ghorabaee, E. K. Zavadskas, Z. Turskis et al., "A new combinative distance-based assessment(codas) method for multi-criteria decision-making," Economic Computation and Economic Cybernetics Studies and Research, vol. 50, no. 3, pp. 25-44, 2016. 